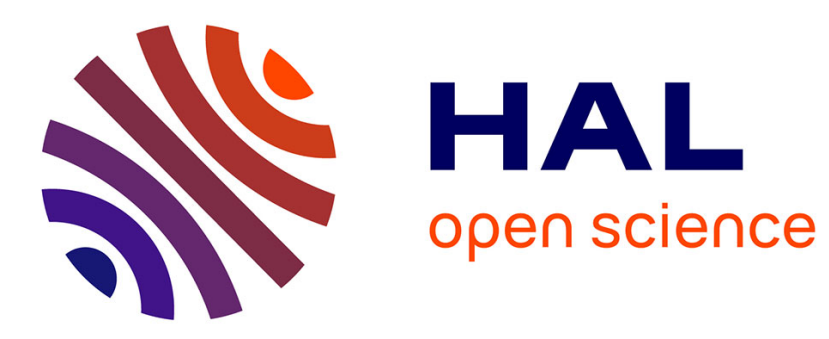

\title{
First results of the "Earth Radiation Budget and Clouds" operational algorithm
}

Frédéric Parol, Jean-Claude Buriez, Claudine Vanbauce, Pierre Couvert, Geneviève Sèze, Philippe Goloub, Sylvain Cheinet

\section{To cite this version:}

Frédéric Parol, Jean-Claude Buriez, Claudine Vanbauce, Pierre Couvert, Geneviève Sèze, et al.. First results of the "Earth Radiation Budget and Clouds" operational algorithm. IEEE Transactions on Geoscience and Remote Sensing, 1999, 37 (3), pp.1597 - 1612. 10.1109/36.763273 . hal-00811146

\section{HAL Id: hal-00811146 https://hal.science/hal-00811146}

Submitted on 10 Apr 2013

HAL is a multi-disciplinary open access archive for the deposit and dissemination of scientific research documents, whether they are published or not. The documents may come from teaching and research institutions in France or abroad, or from public or private research centers.
L'archive ouverte pluridisciplinaire HAL, est destinée au dépôt et à la diffusion de documents scientifiques de niveau recherche, publiés ou non, émanant des établissements d'enseignement et de recherche français ou étrangers, des laboratoires publics ou privés. 


\title{
First Results of the POLDER "Earth Radiation Budget and Clouds" Operational Algorithm
}

\author{
Frédéric Parol, Jean-Claude Buriez, Claudine Vanbauce, Pierre Couvert, \\ Geneviève Sèze, Philippe Goloub, and Sylvain Cheinet
}

\begin{abstract}
The POLDER instrument is devoted to global observations of the solar radiation reflected by the earthatmosphere system. Algorithms of the "Earth Radiation Budget and Clouds" processing line implemented at the French Space Center are applied to ADEOS-POLDER data. First results on derived cloud properties are presented from POLDER level 2 data of 10 November 1996 and level 3 products of June 1997.

A good correlation is observed between the POLDER cloud detection algorithm and the Dynamical Clustering Method applied to METEOSAT data. The multidirectional capability of POLDER appears useful to check schemes of cloud optical thickness retrieval. As expected, a water droplet model is suitable for liquid water clouds and inadequate for ice clouds. That indirectly validates our algorithm of cloud phase recognition. An apparent pressure is derived from $\mathrm{O}_{2}$-absorption measurements and a Rayleigh cloud pressure from polarization observations. For overcast conditions, the apparent pressure is larger (by more than $100 \mathrm{hPa}$ ) than the Rayleigh pressure chiefly due to the photon penetration effect. For partly cloudy conditions, it can be larger or weaker depending on the surface reflectivity.

Preliminary comparisons between POLDER and ISCCP monthly mean products outline some differences resulting in part from the original characteristics of POLDER.
\end{abstract}

Index Terms-Clouds, polarization, remote sensing.

\section{INTRODUCTION}

$\mathbf{H}$ UMAN activities are increasing the atmospheric concentrations of both greenhouse gases and anthropogenic aerosols, which tend, respectively, to warm and to cool the earth-atmosphere system [22], [11]. Global climate models (GCM's) endeavor to project what the future has in store for the earth, but the large range of possible scenarios mainly comes from the little understood in the climate sensitivity to such perturbations [22]. A major uncertainty in the determination of this sensitivity is the misunderstanding in the feedbacks associated with cloudiness changes and the

Manuscript received April 2, 1998; revised November 18, 1998. This work was supported by CNES, European Economic Community, Région Nord-Pas De Calais, and Préfecture du Nord through EFRO. Meteorological data have been provided by Météo-France. METEOSAT data have been provided by the Centre de Météorologie Spatiale in Lannion. Currently updated information about POLDER project is available from http://polder@wwwprojet.cnes.fr:8060.

F. Parol, J.-C. Buriez, C. Vanbauce, P. Goloub, and S. Cheinet are with the Laboratoire d'Optique Atmosphérique, URA CNRS 713, Université des Sciences et Technologies de Lille, UFR de Physique, 59655 Villeneuve d'Ascq Cedex, France (e-mail: fred@loa.univ-lille1.fr).

P. Couvert is with the Laboratoire des Sciences du Climat et de l'Environnement, Centre d'Etudes de Saclay, 91191 Gif-sur-Yvette, France.

G. Sèze is with the Laboratoire de Météorologie Dynamique, CNRS, Université P. et M. Curie, Jussieu, 75252 Paris Cedex 05, France.

Publisher Item Identifier S 0196-2892(99)03575-5. difficulty of GCM's to correctly account for cloud-radiationclimate interactions [8], [9], [36]. Indeed, cloud-radiation interactions are really complex and depend on numerous physical parameters such as the cloud macrophysical and microphysical characteristics but also the atmospheric and terrestrial environment. Consequently, GCM's need realistic representation of clouds and their effects on radiation balance at global scale as well as at regional scale. It is essential to correctly simulate the present forcing of clouds on radiation but especially to model what the future forcing of clouds will be. Global observations of cloud properties and global measurements of the effects of clouds on radiation are essential to achieve this objective.

The most comprehensive way to obtain global cloud observations is by means of satellite-based measurements, even if field experiments and ground-based measurements remain essential to support the satellite observations. Satellites can directly observe not only the spatial and temporal variabilities of clouds [33] but also their effects on earth's radiation budget (ERB) at the top of the atmosphere [30], [20]. Since the first satellite images were used [1], satellite observations of clouds and satellite derivation of cloud properties have been widely developed and investigated (see [32] for an almost exhaustive historical summary of cloud algorithms).

POLDER (POLarization and Directionality of the Earth's Reflectances) is a component of a series of new sensors that may provide key information for improving our knowledge of clouds, radiation, and climate interactions. POLDER is a CNES (the French Space Agency) instrument which was on board the Japanese ADEOS (ADvanced Earth Observing Satellite) polar orbiting platform, successfully launched in August 1996. In November 1996, POLDER entered into its nominal acquisition phase and functioned perfectly until ADEOS early end of service in June 1997. POLDER is a multispectral imaging radiometer-polarimeter designed to provide global and repetitive observations of the solar radiation reflected by the earth-atmosphere system [13]. The instrument concept is based on a wide field of view $(\sim 2200 \mathrm{~km})$ telecentric optics, a rotating wheel carrying spectral filters and polarizers, and a charged coupled device (CCD) array of (242 $\times 274$ ) detectors that induces a moderate spatial resolution of $6.2 \mathrm{~km}$. As the ADEOS satellite passes over a scene, up to 14 successive measurements are acquired in eight narrow spectral bands located between 443 and $910 \mathrm{~nm}$. The POLDER level 1 products routinely processed by CNES consist of calibrated radiances and Stokes parameters at full spatial resolution. The 
level 2 and 3 products are split into three processing lines which are the "ERB, water vapor, and clouds" (hereafter noted as "ERB \& clouds"), the "Ocean color and aerosols over the ocean," and the "Land surfaces and aerosols over land" lines. For different reasons put forward in [7], all of the results of the "ERB \& clouds" processing line are averaged at the "superpixel" scale that typically corresponds to $(9 \times 9)$ pixels. The spatial resolution of the super-pixel $\left(0.5^{\circ} \times 0.5^{\circ}\right.$ at the equator, i.e., $\sim 50 \mathrm{~km} \times 50 \mathrm{~km}$ ) appears suitable both for comparison with ISCCP (International Satellite Cloud Climatology Project, [33]) products and for use in connection with ERB instruments like ScaRaB (Scanner for the Earth Radiation Budget) [23] and CERES (Cloud and the Earth's Radiant Energy System) [45].

The "ERB \& clouds" thematic interest takes advantage of the multispectral, multidirectional, and multipolarization capabilities of POLDER to derive useful information on clouds and their effects on short-wave radiation [7]. This paper deals with one of the main goals of the "ERB \& clouds" line which is the derivation of cloud properties, such as cloud amount, cloud optical thickness, cloud pressure, and cloud thermodynamic phase at global scale. The atmospheric water vapor content is presented in a companion paper in this issue [43]. Similarly to many "cloud algorithms" [32], the "ERB \& clouds" processing line uses two basic steps: the cloud detection phase and the cloud properties derivation phase. The first step is crucial since it controls further processing and it has a major impact on determining other products. Particular attention is therefore given to the cloud detection algorithm of the "ERB \& clouds" line; it is a threshold method employing several sequential tests for the presence of clouds. The adjustments of the different tests involved in the algorithm are presented in the next section. The so-derived POLDER pixel identification is compared to a cloud classification applied to METEOSAT data and based on the Dynamical Clustering Method [37]. The following sections present the others cloud properties, cloud optical thickness, cloud pressure, and cloud phase, respectively. The original contribution of POLDER regarding these products is emphasized. The discussions are supported by the analysis of POLDER data acquired on November 10, 1996, especially along three ADEOS orbits over the Atlantic Ocean (orbit numbers 3107-3109), i.e., in the METEOSAT field of view (see Fig. 1). At the end of a validation period foreseen in July 1998, the complete set of POLDER data will be processed by CNES and level 2 and 3 products will be made available to the scientific community. For the moment, the only available monthly synthesis of the "ERB \& clouds" line is for June 1997. Section VI presents the global monthly means of POLDER-derived cloud properties and compares them to the ISCCP products. Finally, Section VII summarizes the results and concludes.

\section{Cloud Amount: The Cloud Detection Algorithm}

The physical principles of the POLDER cloud detection algorithm are extensively developed in [7]. They were based on the analysis of measurements performed by the airborne simulator of POLDER. Since then, POLDER has flown aboard ADEOS, and some adjustments and improvements have been

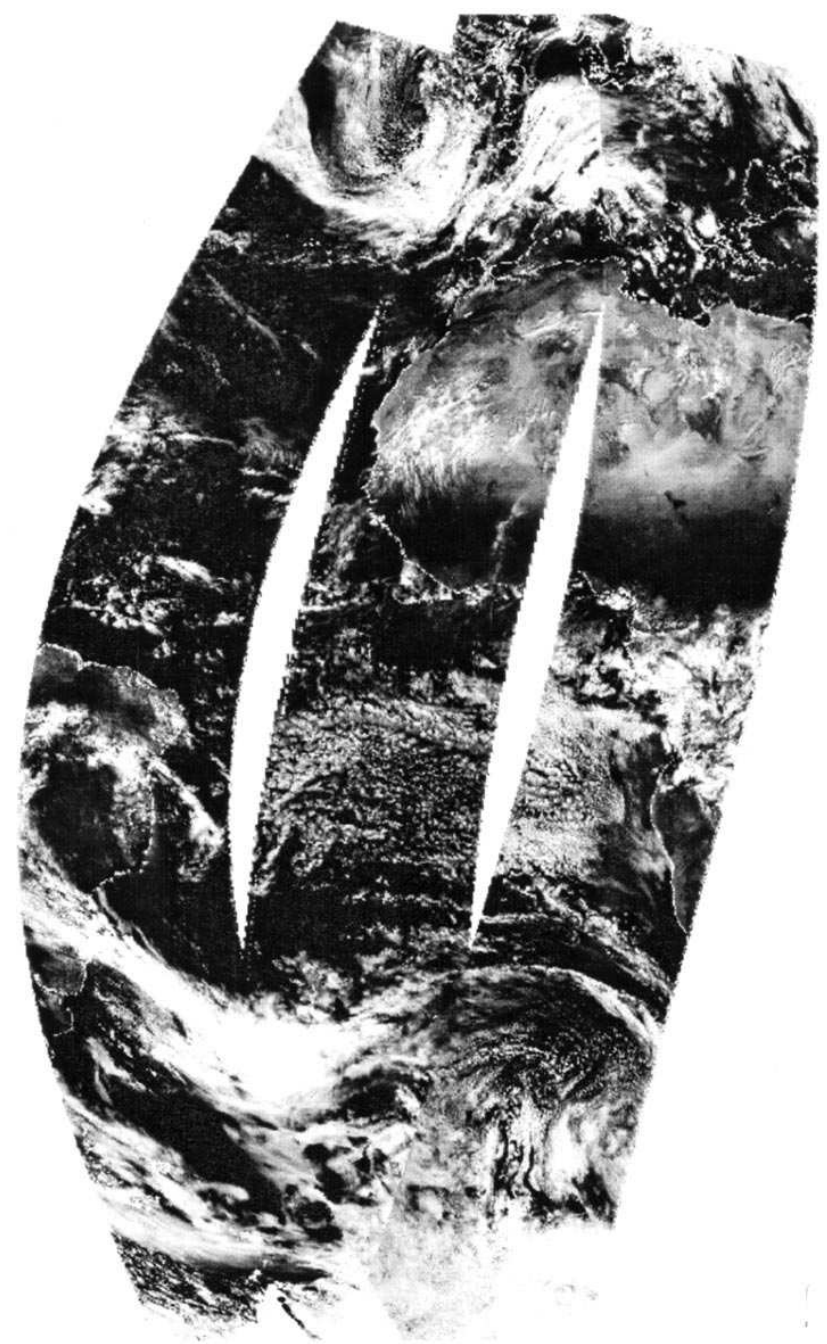

Fig. 1. Image constructed from $670 \mathrm{~nm}$ reflectance measured by POLDER on November 10, 1996 along three ADEOS paths (orbit numbers 3107-3109) over the Atlantic Ocean. Clouds appear as light shades against a darker ocean or land background.

brought to the algorithm. First, this section briefly covers the different threshold tests used in the algorithm and presents the methodology used to adjust the different threshold values. This consists mainly in analyzing the coherence of results from the various tests involved in the algorithm. The validation of the cloud identification is emphasized through comparison with the results of the Dynamical Clustering Method applied to METEOSAT satellite observation [37].

The cloud detection algorithm of the "ERB \& clouds" line is mainly based on a series of sequential threshold tests applied to each individual pixel $(6.2 \mathrm{~km})$ and for every viewing direction. Some of these tests use the spectral reflectance defined as $R_{\lambda}=\pi L_{\lambda} /\left(\cos \theta_{s} E_{\lambda}\right)$, where $L_{\lambda}$ is the measured spectral radiance, $\theta_{s}$ is the solar zenith angle, and $E_{\lambda}$ is the spectrally averaged solar irradiance at the top of the atmosphere. Four tests aim at detecting clouds, and a pixel is declared cloudy when one of these tests proves positive.

1) An "apparent" pressure $P_{\text {app }}$ is derived from the ratio of reflectance measured in the channels centered at 763 and $765 \mathrm{~nm}$ (see Section IV). The pixel is labeled 
cloudy if $P_{\text {app }}$ is markedly lower than the sea-surface pressure $P_{\text {surface }}$. The threshold applied to $P_{\text {surface }}-$ $P_{\text {app }}$ depends on the ratio between the molecular and the total reflectance at $765 \mathrm{~nm}, R_{\mathrm{mol}} / R^{*}$ [42].

2) A pixel is declared cloudy if the measured reflectance at wavelength $\lambda, R_{\lambda}$ ( $\lambda=865 \mathrm{~nm}$ over ocean and $\lambda=443$ $\mathrm{nm}$ over land) is significantly larger than its clear-sky estimate $R_{\lambda}^{\text {clear }}$. Over ocean, a large threshold value $(15 \%)$ is chosen in order to avoid classifying aerosols as clouds. The same value is chosen over land, but the spatial variability is taken into account.

3) For scattering angles less than $140^{\circ}$, the molecular optical thickness $\tau_{443}$ of the atmospheric layer above the observed surface (cloud or sea-surface) is directly derived from the polarized reflectance at $443 \mathrm{~nm}$. It is compared to the total molecular optical thickness of the atmosphere $\tau_{443}^{\text {clear }}$. If the $\tau_{443}^{\text {clear }}-\tau_{443}$ difference is above threshold, the pixel is rejected as cloud contaminated. In [7] the threshold was set to a constant value. In the new version of the algorithm, it varies as a linear function of the air-mass factor.

4) The polarized radiance at $865 \mathrm{~nm}$ presents different features for clear-sky and for cloud conditions specifically in the rainbow direction (see Section V). A pixel is identified as cloud-contaminated if the actual polarized radiance is outside the expected range for clear-sky conditions. This range is now defined as a function of the scattering angle.

If all of the previous tests prove negative, two more tests are added in order to identify the clear pixels.

5) A pixel that has not been declared cloudy is labeled as clear if $R_{\lambda}-R_{\lambda}^{\text {clear }}$ ( $\lambda=865 \mathrm{~nm}$ over ocean and $\lambda=443 \mathrm{~nm}$ over land) is small enough $(<2 \%)$.

6) Finally, a pixel is expected to be clear if its reflectance exhibits a large spectral variability. Practically, following [5] the $R_{865} / R_{443}$ ratio was found to be a better indicator than the $R_{865} / R_{670}$ ratio initially considered in [7]. Over ocean, a pixel is declared as cloud-free if the $R_{865} / R_{443}$ ratio is less than 0.4 . Over land surface, this ratio has to be more than 1.2.

The different thresholds presented above have been adjusted according to the following philosophy. When adjusting the four first tests, the reflectance threshold test, $R_{\lambda}-R_{\lambda}^{\text {clear }}<2 \%$ is considered as a reference test. Indeed, all the pixels that satisfy this test for all the viewing directions are expected to be clear. Consequently, the reflectance threshold test is used as an indicator of the relevance of the different "cloud" thresholds. At this stage, the philosophy of the cloud detection algorithm is to adjust the "cloud" thresholds in order to make sure that all the four tests prove negative when the pixel is clear. When detecting the cloud-free pixels, a similar approach is adopted. Pixels are expected to be "cloudy" if the reflectance threshold test, $R_{\lambda}-R_{\lambda}^{\text {clear }}>15 \%$, is satisfied whatever the direction of view. The spectral variability thresholds are thus adjusted in such a way that practically no cloudy pixel is declared as clear. Illustration of this methodology can be found in [38].
If a POLDER pixel does not satisfy at least one of the six tests described above, it remains unclassified for a given viewing direction. However, if this pixel is labeled as clear (or cloudy) in some viewing directions and undetermined in all the other ones, then it is labeled as clear (or cloudy) for all the directions. If the pixel remains undetermined, it is then relabeled as clear or cloudy depending on the classification of the neighboring pixels and the spatial variability of $R_{670}$. Afterwards, when all of the elementary pixels are identified as cloud-free or cloudy, the cloud cover is computed at the superpixel scale $(\sim 9 \times 9$ pixels $)$, direction by direction. An example of so-derived global distribution of the monthly mean cloud cover retrieved from ADEOS/POLDER data is presented in Section VI.

A first validation of the POLDER cloud identification algorithm goes through a comparison with the results of the Dynamical Clustering Method [37] applied to METEOSAT data acquired every $30 \mathrm{~min}$ between 7 and 14 UTC from October 30 to November 10, 1996. The spatial resolution of the METEOSAT data is $5 \mathrm{~km}$ at nadir. The Dynamical Clustering Method uses two spectral parameters, the infrared and visible radiances and two structural parameters, the local spatial standard deviation of the visible and infrared radiances (computed for $3 \times 3$ neighboring pixels). These data are processed following [29] for five latitudinal regions over ocean and six regions over land. The result is a set of cloud type classifications valid between 7 and 14 UTC for the October 30-November 10, 1996 period. From this set, any ADEOSPOLDER path in the METEOSAT field of view can be simulated with a time lag of $\pm 15 \mathrm{~min}$.

The POLDER and METEOSAT cloud covers are compared for the three ADEOS paths (orbit numbers 3107-3109) on November 10 (Fig. 1). The proportion of clear (overcast) pixels is $28 \%(49 \%)$ in the METEOSAT classification and $34 \%(53 \%)$ in the POLDER one. The smaller clear pixel percentage in the METEOSAT classification is compensated by a larger percentage of partially covered pixels (small cumulus, cloud edges, very thin cirrus) than in the POLDER cloud classification. Note that "partly" does not have the same meaning for METEOSAT and POLDER pixels. In the former, it is used for METEOSAT pixels that are expected to be partly covered by clouds. In the latter, it is used for POLDER pixels that are labeled as cloudy for some viewing directions and clear for the others. The co-occurrence matrix obtained from the pixel-to-pixel comparison of the two classifications (Table I) shows that $76 \%$ of the pixels belong to the same class and only $1.7 \%$ belong to opposite classes (clear/overcast or overcast/clear). The percentage of pixels declared clear by POLDER but declared cloud-contaminated by METEOSAT $(9 \%)$ is larger than the opposite case (3\%). Only $13 \%$ of these anomalous pixels are overcast in the first case, and $17 \%$ in the second case. Tables II and III, respectively, give the distribution of the METEOSAT cloud types for each of the three POLDER classes and the distribution of the three POLDER classes for each of the METEOSAT cloud types. The overcast cloud types (low, middle, multilayer, cirrus, high thick clouds) have at least $85 \%$ of their pixels belonging to the overcast class in the POLDER classification and less than 
TABLE I

Co-Occurrence Matrix Obtained From the Pixel-to-Pixel COMPARISON OF METEOSAT AND POLDER IDENTIFICATION FOR THE 3 POLDER-ADEOS PATHS OF FIG. 1

\begin{tabular}{l|rrr}
\hline \multirow{2}{*}{ METEOSAT } & \multicolumn{3}{|c}{ POLDER } \\
& Clear & Partly & Overcast \\
Clear & & & \\
Partly & $25.1 \%$ & $2.5 \%$ & $0.5 \%$ \\
Overcast & $7.9 \%$ & $6.6 \%$ & $8.0 \%$ \\
& $1.2 \%$ & $3.9 \%$ & $44.3 \%$ \\
\hline
\end{tabular}

TABLE II

Distribution of the Meteosat Cloud Types in Each of the Three POLDER Classes For the Three POLDER-ADEOS Paths of Fig. 1

\begin{tabular}{|c|c|c|c|}
\hline \multirow{2}{*}{$\begin{array}{l}\text { METEOSAT } \\
\text { Cloud types }\end{array}$} & \multicolumn{3}{|c|}{ POLDER classes } \\
\hline & Clear & Partly & Overcast \\
\hline $28.1 \%$ clear & $89 \%$ & $9 \%$ & $2 \%$ \\
\hline $9.6 \%$ nearly clear & $46 \%$ & $28 \%$ & $26 \%$ \\
\hline $7.0 \%$ thin edges & $40 \%$ & $38 \%$ & $22 \%$ \\
\hline $5.9 \%$ partly cloudy & $12 \%$ & $21 \%$ & $68 \%$ \\
\hline $9.2 \%$ low clouds & $2 \%$ & $3 \%$ & $96 \%$ \\
\hline $7.4 \%$ middle clouds & $3 \%$ & $6 \%$ & $9 \%$ \\
\hline $5.8 \%$ multi-layers & $3 \%$ & $13 \%$ & $85 \%$ \\
\hline $4.2 \%$ thin cirrus clouds & $11 \%$ & $32 \%$ & $57 \%$ \\
\hline $11.5 \%$ cimus clouds & $2 \%$ & $10 \%$ & $89 \%$ \\
\hline $11.3 \%$ high thick clouds & $0 \%$ & $0 \%$ & $100 \%$ \\
\hline
\end{tabular}

$3 \%$ of them are classified as clear. An exception is the thin cirrus class. For the partly cloudy types, the percentage of clear POLDER pixels decreases as the subpixel cloud cover is expected to increase. Study of the spatial neighboring of these partially covered METEOSAT pixels shows that when they are declared clear by POLDER, the percentage of clear METEOSAT pixels in the neighboring is larger than in the other cases.

The cloud cover derived from POLDER compares well with the METEOSAT cloud classification on an instantaneous basis and at the pixel scale. The percentage of full agreement between POLDER and METEOSAT (76\%) is close to the $81 \%$ which is found by comparing the METEOSAT classification with itself by introducing a shift of one pixel. However, in this last case, only $0.2 \%$ of the pixels are classified in opposite categories against $1.7 \%$ in the POLDER-METEOSAT comparison. This discrepancy between POLDER and METEOSAT classifications comes from the differences both in the observations and the algorithms. The METEOSAT algorithm is very sensitive to a very small spatial variability of radiance values close to surface ones. In the POLDER scheme, thresholds have been set up to avoid the inclusion of "false clouds" such as Saharan dust. When the apparent pressure threshold and/or the reflectance threshold is decreased, the percentage of clear POLDER pixels declared clear by METEOSAT increases, but the percentage of clear METEOSAT pixels declared cloudy by POLDER increases, too. This comparison appears encouraging though there are some discrepancies especially for the partly cloudy and the thin cloud cases.

One has to keep in mind that the aim of the "ERB \& clouds" processing line is to derive cloud properties and not to detect surface parameters. Consequently, the cloud detection algorithm is very different from a cloud-clearing algorithm. The previous discussion highlights that broken cloudiness as well as thin cloud cover are sometimes classified as clear by the POLDER pixel identification scheme. In fact, one verifies that the different thresholds of the POLDER algorithm have been adjusted in such a manner that questionable cloud cases as well as thick aerosol layers are rejected as clear. Generally speaking, it seemed to the authors that it was preferable not to allocate to an entire POLDER pixel some mean cloud properties corresponding only to a small fraction of the pixel. However, this philosophy may have some impact on the final results, as illustrated in Section VI.

\section{CLOUd OPTICAL ThickNesS}

Cloud optical thickness is directly related to the ice/water content and is thus a key parameter in cloud modeling. It can be derived from bidirectional reflectance measurements. However, this needs some assumptions both on cloud microphysics and on cloud morphology and spatial distribution. Cloud fields are commonly viewed as a single and homogeneous planeparallel layer composed of prescribed particles despite possibly large effects due to both cloud heterogeneities (e.g., [25], [10]) and different particles [28]. Unlike the usual scanner radiometers, POLDER provides up to 14 quasi-simultaneous reflectance measurements of a geographical target. While it is always possible to find a cloud model that satisfies one single bidirectional observation of a given target, it is not so easy to fulfill the complete set of 14 observations. Consequently, POLDER not only allows the determination of cloud optical thickness under some hypotheses, but it also enables us to test the validity of these hypotheses.

A cloud water droplet model is used in our algorithm that operationally derives cloud optical thickness from ADEOSPOLDER data [7]. The cloudy pixels are assumed fully covered by a plane-parallel layer composed of liquid water droplets with an effective radius of $10 \mu \mathrm{m}$ and an effective variance of 0.15 [18]. In these conditions, the optical thickness is the only cloud property that is allowed to vary. This model is similar to the one used in the first ISCCP analysis [33]. The uncertainties due to the use of this model have been discussed in [32].

An example of global distribution of the monthly mean cloud optical thickness retrieved from ADEOS-POLDER data is presented in Section VI. The purpose here is to illustrate the ability to test the cloud model used. To do that, for the cloudy situations observed over ocean during three ADEOS 
TABLE III

Distribution of the Three POLDER Classes in Each of the METEOSAT Cloud Types for the Three POLDER-ADEOS Paths of Fig. 1

\begin{tabular}{|c|c|c|c|c|c|c|c|c|c|c|}
\hline \multirow[b]{2}{*}{ POIDDER } & \multicolumn{10}{|c|}{ METEOSAT cloud types } \\
\hline & Clear & Nearly & Thin & Partly & Iow & Middle & Multi- & Thin & Cimpls & High \\
\hline classes & & clear & edges & cloudy & chouds & clouds & layers & cirtus & clouds & Thick \\
\hline $34.2 \%$ Clëall & $73 \%$ & $13 \%$ & $8 \%$ & $2 \%$ & $0 \%$ & $1 \%$ & $0 \%$ & $1 \%$ & $1 \%$ & $0 s_{i}$ \\
\hline $13.0 \%$ Pantly & $19 \%$ & $21 \%$ & $20 \%$ & $9 \%$ & $2 \%$ & $4 \%$ & $6 \%$ & $10 \%$ & $8 \%$ & $0 \%$ \\
\hline $52.8 \%$ overest & $1 \%$ & $5 \%$ & $3 \%$ & $8 \%$ & $17 \%$ & $13 \%$ & $9 \%$ & $5 \%$ & $19 \%$ & $2 ! \%$ \\
\hline
\end{tabular}

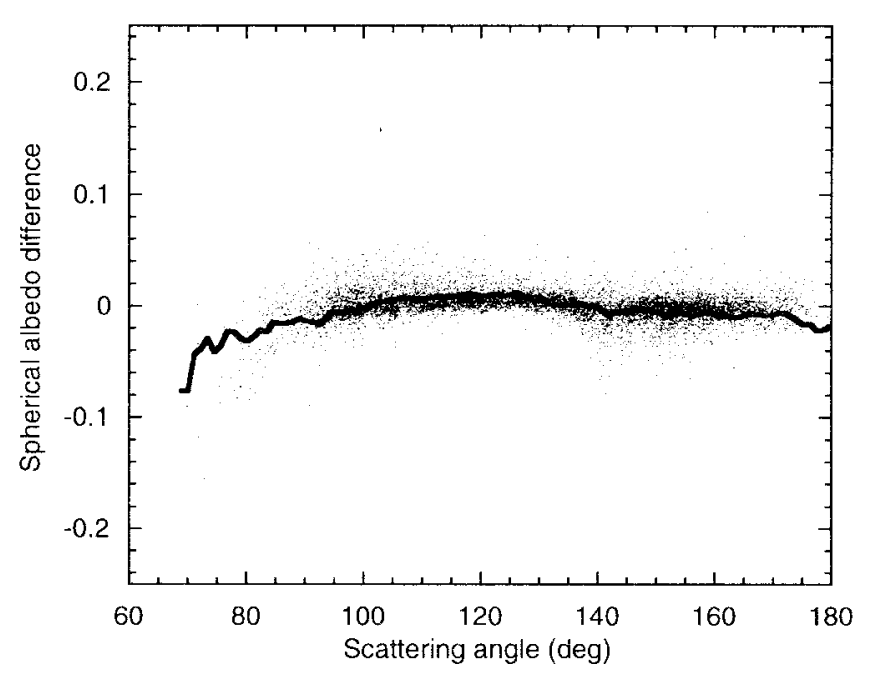

(a)

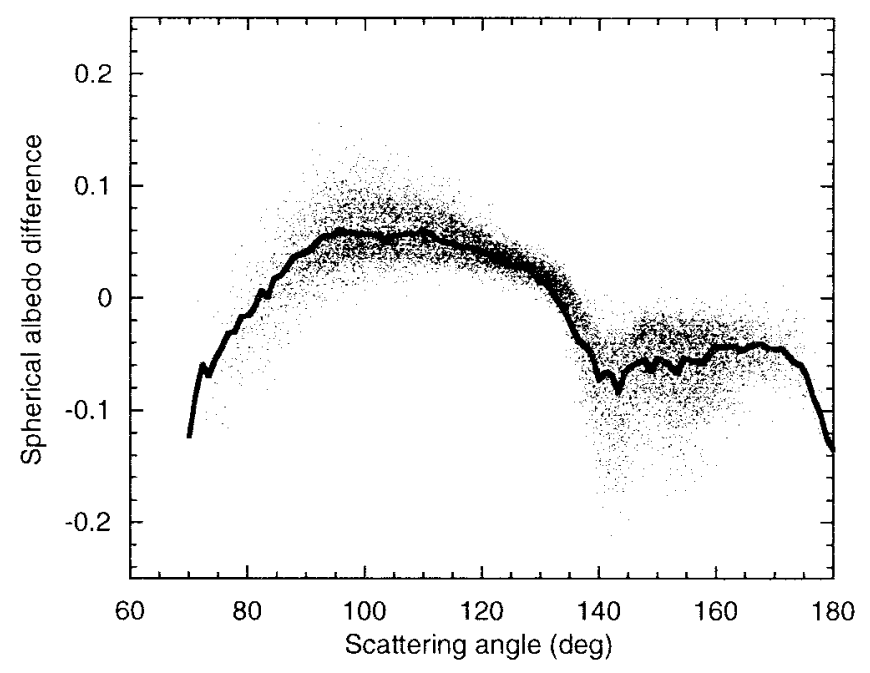

(b)

Fig. 2. Differences between the "directional" values of cloud spherical albedo and their mean value as a function of scattering angle for (a) liquid water clouds and (b) ice clouds. The wavelength is $670 \mathrm{~nm}$. The line corresponds to the average difference. POLDER data corresponds to ADEOS orbits $3107-3109$. overpasses (orbit numbers 3107-3109), we make use of the $N(\leq 14)$ "directional" values of cloud optical thickness, given in the "ERB \& clouds" products. Since the retrieval is based on the standard cloud droplet model, these $N$ values are expected to be close to one another in the case of liquid water clouds and dispersed in the case of ice clouds. By another way, for each cloudy pixel the thermodynamic phase is identified following the method described in Section V. We thus select the super-pixels only composed of pixels for which the phase is found liquid and the super-pixels for which the phase is ice whatever the pixel. For every superpixel observed under at least seven directions, we calculate the difference between each of the "directional" values of optical thickness and their mean value. More precisely, we make use of a representation, introduced in the ISCCP scheme, that is equivalent in radiative energy amount. Indeed, the variability of the cloud properties we are interested in is important according to their contribution to the earth radiation budget. Additionally, as the basic measurements are radiances, the precision of the calculated differences is more easily interpretable in energy rather than in optical thickness. Practically, the calculated parameter is the cloud spherical albedo (over a black surface) which is a one-to-one function of the optical thickness (see [34, Fig. 3.13]).

These cloud spherical albedo differences are reported as a function of scattering angle for the selected liquid water clouds in Fig. 2(a). On average, the liquid water clouds appear well represented by the standard droplet model. The absolute difference of retrieved spherical albedo is typically 0.01. Only about ten superpixels, located near a depression off Iceland, notably depart from this good behavior; the large spherical albedo differences are certainly due to shortcomings in the cloud phase detection for these ambiguous multilayered cloud systems. The spherical albedo difference averaged over the 2278 superpixels classified as liquid water clouds remains very close to zero for all the scattering angles larger than $90^{\circ}$. The values of scattering angle around $80^{\circ}$ correspond to large values of the solar and/or the viewing zenith angle, which may induce a serious weakness of the plane-parallel approximation [25]. However, note that the abrupt decrease of the spherical albedo difference near $70^{\circ}$ corresponds to the 
ambiguous cases mentioned above and must not be considered as representative of the liquid water clouds.

The spherical albedo differences calculated for the superpixels classified as ice clouds are reported in Fig. 2(b). As expected, it clearly appears that the liquid water droplet model is not suitable for ice clouds. The difference of retrieved spherical albedo often reaches values as large as \pm 0.1 . The value of the spherical albedo difference averaged over the 1197 superpixels varies by 0.12 when the scattering angle varies from $100^{\circ}$ to about $140^{\circ}$. The minimum observed near $140^{\circ}$ is related to the peak of the phase function of the water droplet model in the rainbow direction. A smoother phase function would give a better agreement in the treatment of ice clouds.

However, the standard water droplet model which is used in the POLDER operational algorithm-a cloud droplet radius of $10 \mu \mathrm{m}$-is in good agreement with mean values retrieved from near-infrared radiance observations over lowlevel clouds: about $11-12 \mu \mathrm{m}$ in maritime clouds and 8-9 $\mu \mathrm{m}$ in continentals clouds [17]. On the opposite, many studies have shown that the single-scattering properties of ice cloud particles differ substantially from those of liquid water spheres (see [28] and references therein). For that reason, an ice fractal polycrystal model, which is expected to be representative of irregularly shaped and randomly oriented ice particles, was introduced in the treatment of cold clouds in the recent ISCCP re-analysis [34]. On the other hand, the analysis of airborne POLDER data acquired during the EUCREX'94 (European Cloud and Radiation Experiment) campaign confirmed that the standard water droplet model is suitable for stratocumulus and the ice polycrystal model is more adequate for cirrus clouds [14].

Thus, the POLDER bidirectional reflectance measurements appear useful to check the schemes of cloud optical thickness retrieval. In the near future, different cloud particle models will be investigated in order to minimize the angular variability of the cloud spherical albedo.

\section{Cloud Pressure}

Together with cloud optical thickness, one of the most important cloud properties with respect to global climate changes is cloud height. Several techniques for deriving cloud altitude from satellite have already been developed, generally using radiances in the $15 \mu \mathrm{m} \mathrm{CO} \mathrm{CO}_{2}$ band (e.g., [40], [27]) or in the atmospheric windows (e.g., [31], [26]). Two different methods were developed to retrieve cloud pressure from ADEOS-POLDER data [7]. Here we present the first comparison between these two cloud pressures, respectively, derived from absorption measurements in the oxygen A-band and from spectral polarization measurements.

The algorithm of derivation of the "apparent pressure" $P_{\text {app }}$ is extensively described in [7]. It is based on a differential absorption technique using the radiances measured in the POLDER narrow-band and wide-band channels centered on the oxygen A-band. In this algorithm, $P_{\text {app }}$ is calculated both for clear and for cloudy conditions (cf., Section II; see also [42]). Here we consider only the cloudy conditions. The atmosphere is assumed to behave as a pure absorbing medium overlying a perfect reflector located at pressure $P_{\text {app }}$. Because all scattering effects are neglected, $P_{\text {app }}$ is not the cloud top pressure; it is somewhat of a mean pressure, between the bottom and the top of a single cloud or of a multilayered cloud system. This difference between $P_{\text {app }}$ and the cloud top pressure can be amplified when the ground influence is not negligible. A correction for this effect, proposed in [7], is yet to be validated and is not considered here.

Another retrieved cloud pressure is the so-called "Rayleigh cloud pressure," $P_{\text {Ray }}$, derived from polarization measurements at $443 \mathrm{~nm}$. At this wavelength, the polarized reflectance is mainly related to the atmospheric molecular optical thickness above the observed cloud, at least for scattering angles ranging from $80^{\circ}$ and $120^{\circ}$ and outside the sunglint direction. A correction is introduced to remove the small contamination by the cloud layer itself as explained in [7]. The pressure $P_{\text {Ray }}$ is then directly proportional to the retrieved molecular optical thickness. That pressure is thus expected to be close to the cloud top pressure, at least when the whole signal comes from the molecules situated above the cloud, that needs overcast conditions.

Fig. 3 compares the Rayleigh cloud pressure to that derived from $\mathrm{O}_{2}$ absorption for the clouds observed during the three selected ADEOS overpasses. As expected, $P_{\text {app }}$ is almost always larger than $P_{\text {Ray }}$ for overcast conditions [Fig. 3(a), (b)]. The mean difference is $140 \mathrm{hPa}$ for the 2776 oceanic superpixels and $209 \mathrm{hPa}$ for the 219 continental ones. A comparable difference was observed for optically thick clouds between $P_{\text {app }}$ and the cloud top pressure derived from the brightness temperature measured in the $11-\mu \mathrm{m}$ channel of METEOSAT [42]. These differences are thought to be chiefly due to the photon penetration effect that strongly affects the retrieval of the pressure from $\mathrm{O}_{2}$ absorption measurements. This effect is known to be more negligible as the volume scattering coefficient is larger [46]. That is the case of maritime stratocumulus clouds for which $P_{\text {app }}$ is much closer to $P_{\text {Ray }}$ [see the range 900-1000 $\mathrm{hPa}$ in Fig. 3(a)].

The comparison between $P_{\text {app }}$ and $P_{\text {Ray }}$ appears more complex for the partly cloudy superpixels [Fig. 3(c) and (d)]. The difference $P_{\text {app }}-P_{\text {Ray }}$ remains positive over land but is very often negative over ocean. The mean difference is 225 $\mathrm{hPa}$ for the 711 continental superpixels but $-32 \mathrm{hPa}$ for the 3462 oceanic ones. When the cloud cover tends toward zero, the retrieved pressures do not tend necessarily to the surface pressure $P_{\text {surface. }}$ The Rayleigh pressure tends to $P_{\text {surface }}$ only if there is no additional polarization by the surface. The apparent pressure tends to $P_{\text {surface }}$ only if all of the reflected light comes from the surface. Practically, $P_{\text {app }}$ is close to $P_{\text {surface }}$ for highly reflecting surfaces but can be as weak as $500 \mathrm{hPa}$ for dark surfaces such as the ocean outside the region of the solar specular reflection [42]. Therefore, for partly cloudy pixels, $P_{\text {Ray }}$ is generally larger than the actual cloud top pressure and $P_{\text {app }}$ is weaker or larger than the cloud mean pressure depending on whether the surface is dark or bright. That explains that $P_{\text {app }}-P_{\text {Ray }}$ is generally positive for partly cloudy superpixels over land [Fig. 3(d)] but is now negative now positive over ocean depending on the relative contribution of the cloud in the observed reflectance [Fig. 3(c)]. 


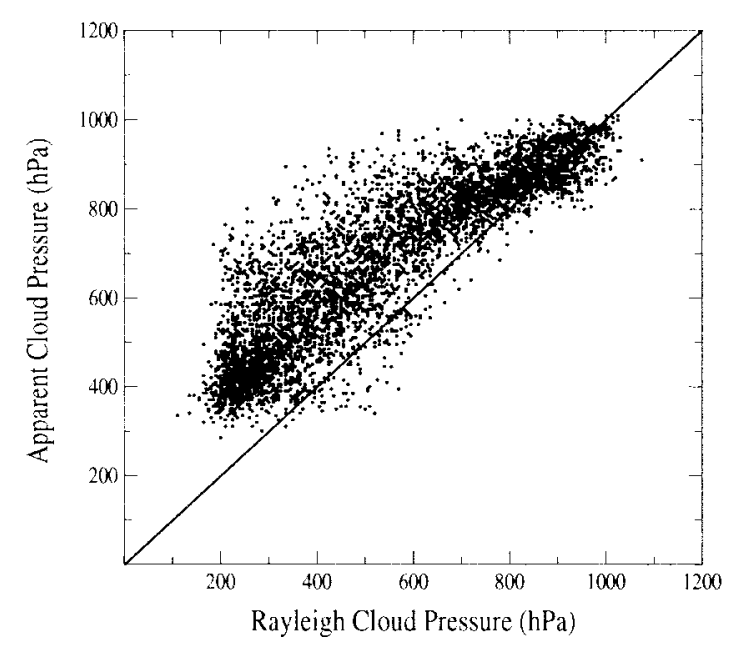

(a)

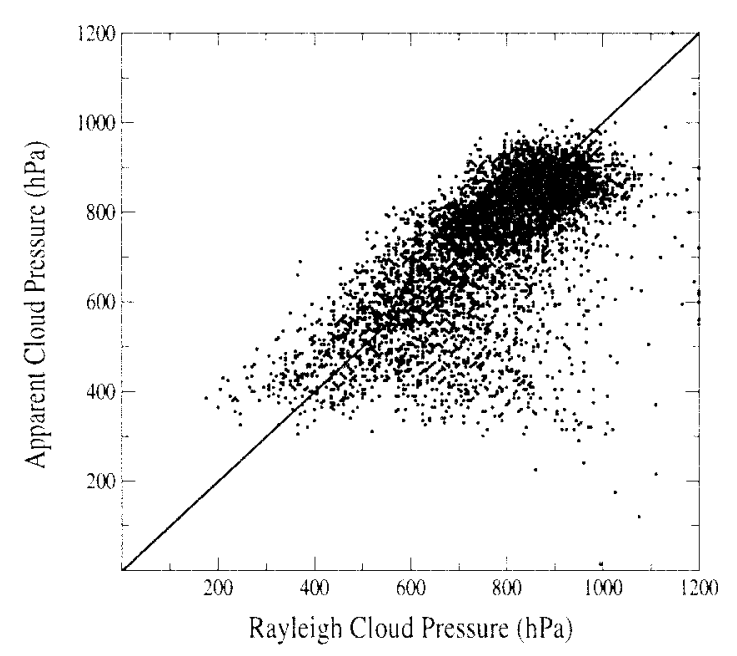

(c)

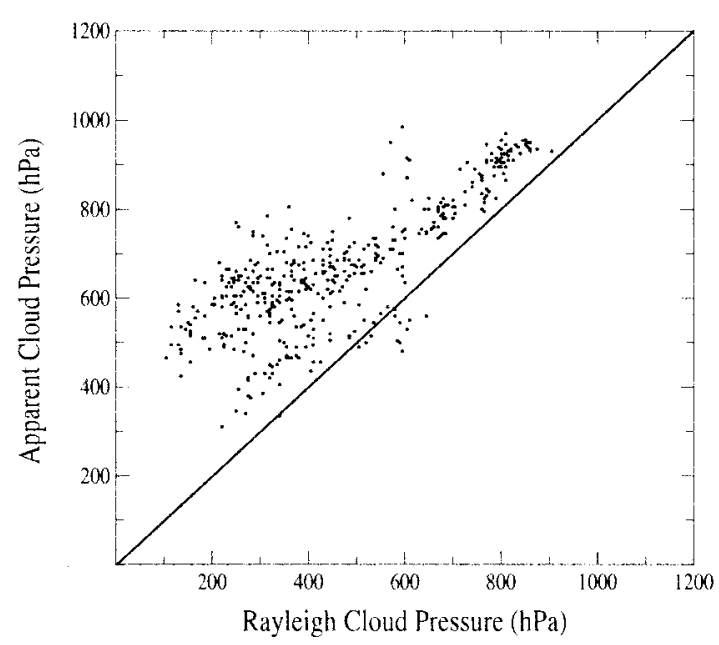

(b)

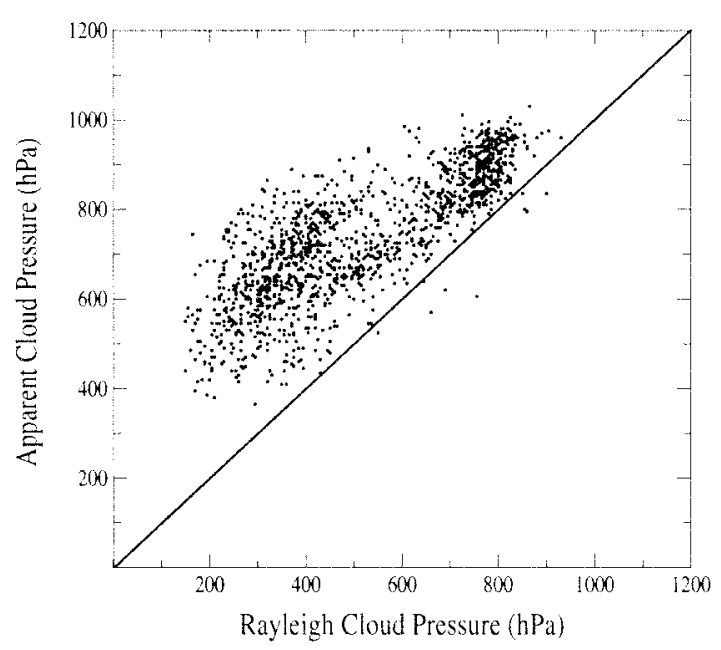

(d)

Fig. 3. Apparent cloud pressure derived from $\mathrm{O}_{2}$ absorption versus Rayleigh cloud pressure derived from polarization at $443 \mathrm{~nm}$, for overcast conditions over (a) ocean and (b) land and for partly cloudy conditions over (c) ocean and (d) land. POLDER data correspond to ADEOS orbits 3107-3109.

\section{Cloud Thermodynamic Phase}

An improved algorithm for remotely determining the cloudtop thermodynamic phase is described hereafter. The algorithm utilizes near-infrared polarized reflectance over a large range of scattering angles in order to discriminate between ice and liquid water phases. Indeed, theoretical as well as experimental studies have shown that polarized signatures of water droplets and ice particles are quite different [15], [16], [6], [35], [12].

Considering a cloudy system observed from satellite, the polarized component of the upward radiance is mainly formed in the upper cloud layer [15]. Around $80 \%$ of the singlescattered radiation reflected by the cloud arises from the upper hundred meters of the layer. In studying cloud polarization, the physical interesting quantity is the polarized reflectance $P R_{\lambda}$, which is less sensitive to multiple scattering effects than the total reflectance [19]. Thus, the polarization features, mainly governed by single scattering, are preserved in $P R_{\lambda}$.

For a large enough optical thickness $(\tau>1)$, the polarized reflectance $P R_{\lambda}$ roughly varies as the cloud polarized phase function, which depends on cloud microphysics properties (shape/size) and refractive index.

In most cases, cloud water droplets are expected to have a particle effective radius ranging between $5 \mu \mathrm{m}$ and $15 \mu \mathrm{m}$. Fig. 4(a) and (b) presents, respectively, theoretical simulations and observations of the main polarization features for scattering angles that can be observed by POLDER. The light scattering by cloud water droplets exhibits a strong maximum about $140^{\circ}$ from the incoming direction. This peak, the socalled primary rainbow, is highly polarized which makes it easily detectable. The maximum and the width of the peak are dependent on the droplet size distribution [15]. Another noticeable property is the neutral point, which is located between $75^{\circ}$ and $120^{\circ}$ according to droplet size. For narrow size distributions, several supernumary bows appear [16]. On the contrary, if the size distribution is relatively broad, no supernumary bow appears. In some cases these properties are used to retrieve the effective radius of liquid water droplets [4]. The last polarization feature that can be observed is the glory, which is centered on the backscattering peak (scattering 


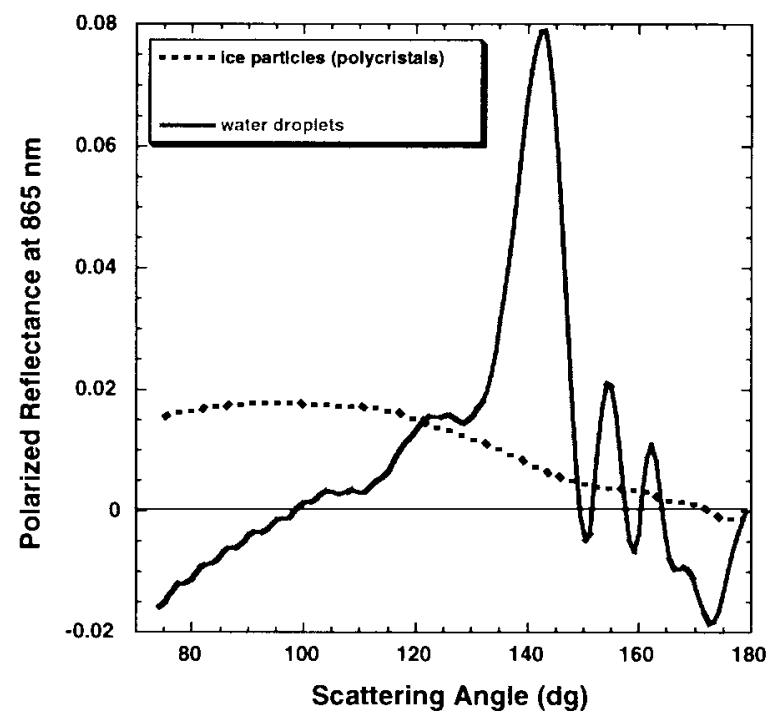

(a)

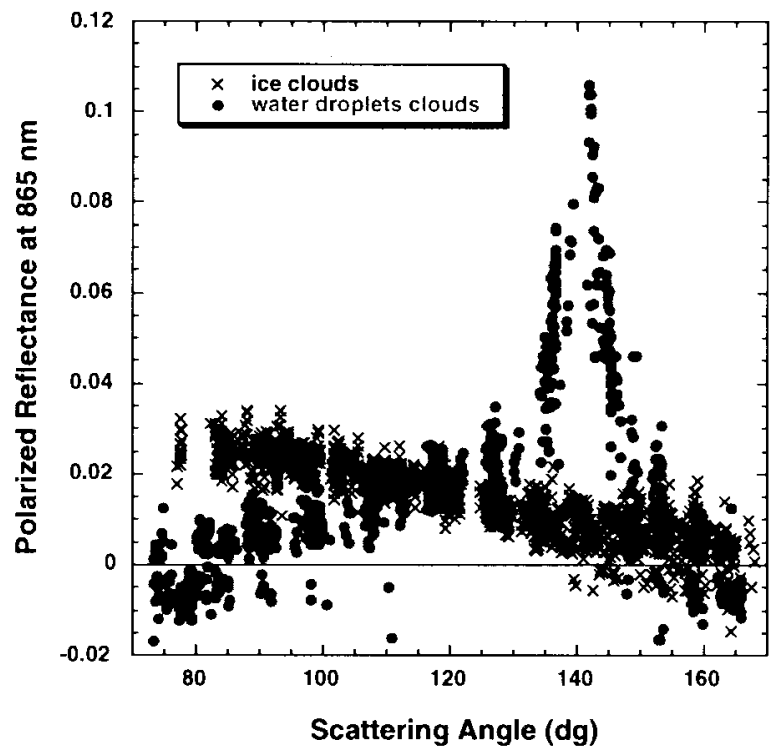

(b)

Fig. 4. Polarized reflectance at $865 \mathrm{~nm}$ as a function of scattering angle. (a) corresponds to simulation in the solar principal plane for polycrystals randomly oriented in space (dashed line) and water spheres of effective radius of $10 \mu \mathrm{m}$ (solid line). In both cases cloud optical thickness is two. The sun zenithal angle is $55^{\circ}$. (b) is an example of polarized reflectance measured by POLDER over cirrus cloud (crosses) and over liquid water cloud (full circle) on November 10, 1996.

angle equal to $180^{\circ}$ ). This is a typical characteristic of water spheres [41].

Unlike water clouds, cirrus clouds are mainly composed of ice crystals with extremely large variabilities in shape and size [21]. Diversity and complexity of ice crystal shape and size depend on temperature and humidity in cloud. For scattering angles that can be observed from space, radiative transfer computations [6], [12] performed for randomly oriented hexagonal particles [Fig. 4(a)] and observations [Fig. 4 (b)] show different important features: i) a generally positive polarization (vibration perpendicular to the scattering plane), ii) a decreasing of the polarization for increasing scattering angles (i.e. negative slope), and iii) a neutral point around $160^{\circ}$.

Since [7], preliminary analysis of polarized reflectances acquired by ADEOS-POLDER has highlighted a possible new way to recognize the cloud thermodynamic phase. The present operational algorithm is described hereafter. Two specific angular ranges are considered. For scattering angles smaller than $110^{\circ}$, the direction of the polarization plane with respect to the scattering plane is predominately $90^{\circ}$ (positive polarized component and negative slope) for ice clouds and $0^{\circ}$ (negative polarization and positive slope) for liquid water clouds. For larger scattering angles (around $140^{\circ}$ ) the two cloud types positively polarize the radiation, but the polarized reflectance is ten times higher for liquid water clouds than for ice clouds. The POLDER angular coverage in term of available scattering angles depends on the latitude and the season. The most complete POLDER angular sampling can give access to these two angular ranges. In some cases, one or both angular domains can be not sampled. The phase detection is based on tests performed in the two scattering angle domains at $865 \mathrm{~nm}$. At this wavelength, the molecular contribution is rather weak and is corrected for by using the Rayleigh cloud top pressure (see Section IV).

The algorithmic principle and results are illustrated in Fig. 5. First, examine the 670-nm reflectance image [Fig. 5(a)] acquired over France on November 10, 1996. The size of the selected area is about $1000 \mathrm{~km} \times 1000 \mathrm{~km}$. Clouds cover a large part of the scene. Now, examine the corresponding polarized reflectance images at $865 \mathrm{~nm}$ for scattering angles around $100^{\circ}$ [Fig. 5(b)] and for scattering angles around $140^{\circ}$ [Fig. 5(c)]. In Fig. 5(b) black pixels correspond to negative polarization near $100^{\circ}$. This characterizes the "liquid" phase. The same pixels exhibit large polarized reflectance around $140^{\circ}$ [Fig. 5(c)]. A combination of the polarization information in these two scattering angle domains leads to label these pixels as "liquid" [Fig. 5(d)]. On the other hand, gray pixels [Fig. 5(b)] correspond to relatively high positive polarization around $100^{\circ}$ and to very small $(<0.01)$ polarization around $140^{\circ}$ [dark pixels in Fig. 5(c)]. The corresponding pixels are labeled "ice" [Fig. 5(d)]. The processing of the POLDER level 1 data thus allows the determination of cloud phase at global scale. Each cloudy "superpixel" of the level 2 POLDER product is finally identified as "liquid," "ice," "mixed" or else "undetermined."

\section{Monthly Mean Cloud Properties}

The level 2 POLDER "ERB \& clouds" products contain for each orbit the retrieved cloud property parameters (cloud cover, cloud pressures, optical thickness, ... ) with their full directional properties and their angular averaging as nondirectional parameters [7]. In level 3 processing, most of the latter, coming from up to 420 orbits, are averaged on a global coverage scale to provide monthly mean climatologies and associated temporal dispersions. For each pixel, the number of daily POLDER observations extend from at most one between $30^{\circ} \mathrm{N}$ and $30^{\circ} \mathrm{S}$ to up to 14 close to the poles. For the June 1997 POLDER data presented here, the number of averaged 


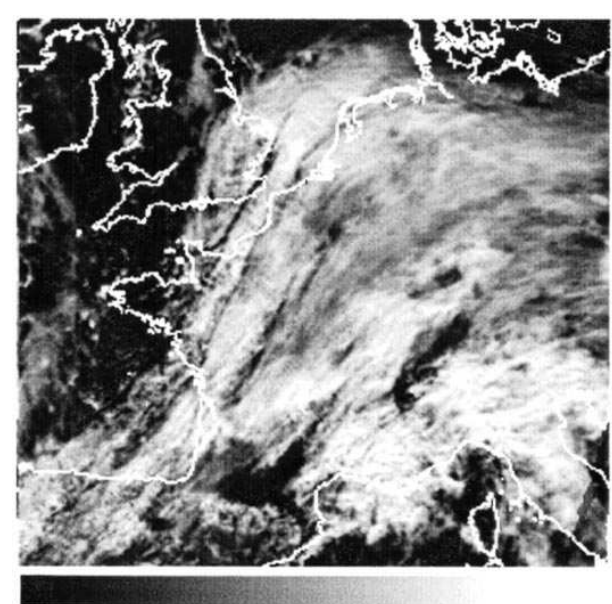

(a)

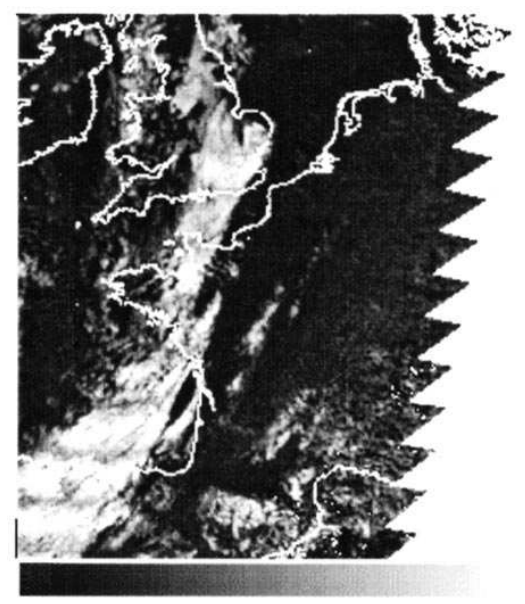

(c)

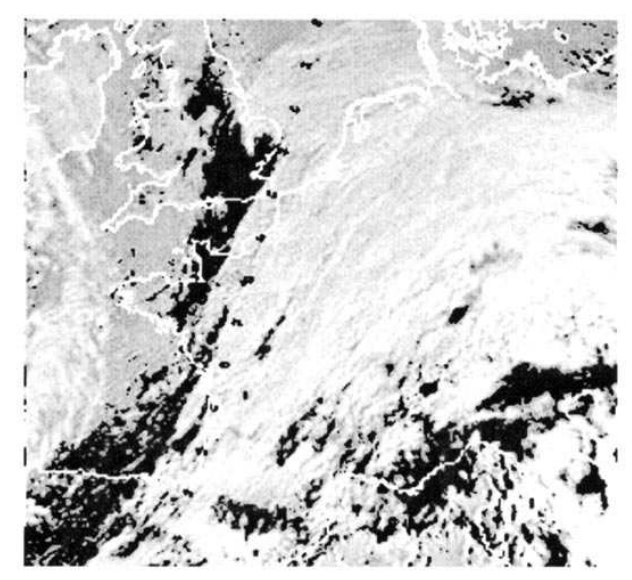

(b)

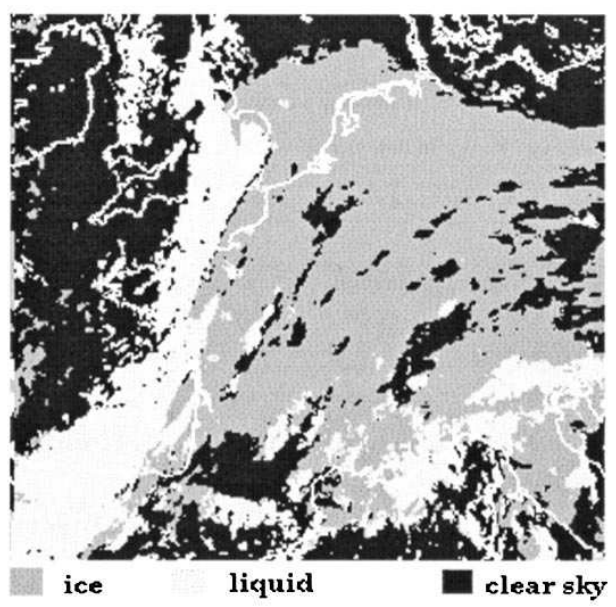

(d)

Fig. 5. Illustration of the cloud thermodynamic phase recognition. (a) Reflectance image in the 670-nm band acquired over France on November 10, 1996. Reflectance dynamic ranges from 0-0.9. (b) Polarized reflectance at $865 \mathrm{~nm}$ for scattering angles close to $100^{\circ}$. Black pixels indicate negative polarization $(-0.04<\mathrm{PR}<0)$. Gray levels are for positive polarization up to 0.02 . (c) Same as (b), but for scattering angles near $140^{\circ}$. Polarized reflectance ranges from 0-0.07. (d) Thermodynamic phase index (black is for clear sky, light gray for liquid, and dark gray for ice). This resulting image is a combination of information contained in (b) and (c).

observations used to construct these climatologies lies, in most cases and depending on cloud cover and latitude, from 15 up to more than 150 observations.

As quoted in Section I, "ERB \& clouds" products are averaged at a $\sim 50 \times 50 \mathrm{~km}^{2}$ scale which corresponds, except very near the poles, to $9 \times 9$ aggregates of elementary POLDER equal area pixels. This low-resolution grid has been constructed in direct relationship with the equal area ISCCP grid, in such a way that each ISCCP cell contains an integer number of these "superpixels" (namely $5 \times 5$, between $80^{\circ} \mathrm{N}$ and $80^{\circ} \mathrm{S}$ ).

As an example of the first available "ERB \& clouds" level 3 monthly synthesis, we present here the June 1997 climatology of four selected parameters (cloud cover, optical thickness, $\mathrm{O}_{2}$ apparent cloud pressure, and Rayleigh cloud pressure) and make a first comparison to interannual means of ISCCP monthly mean data. For this, we have used both C2 (1983-1991) [33] and D2 (1987, 1989-1993) [34] data interpolated at 10:30 a.m. local time, but we will concentrate on the latter, as the most recent reprocessing of the archives.
More exactly, we reprocess the D2-level data from ISCCPD1 data by weighting the cloud optical thickness and cloud pressures by the cloud cover to obtain monthly means coherent with POLDER processing.

In the following, all comparisons of POLDER and ISCCP data are restricted to the $60^{\circ} \mathrm{N}-60^{\circ} \mathrm{S}$ latitude band because of the large snow and sea-ice occurrence near the pole. Furthermore, for all statistical studies, the POLDER observations have been averaged at the ISCCP cell resolution.

\section{A. Cloud Cover}

The POLDER cloud cover for June 1997 is presented in Fig. 6. All the large cloud structures associated with the main climate processes are easily identified and their location is coherent with what we would expect for the month of June: the intertropical convergence zone (ITCZ) along the $10^{\circ} \mathrm{N}$ parallel, large clear-sky area over the deserts of Sahara, SouthWest Africa, and Australia, subtropical zones of heavy cloud cover west of Peru, Angola, California, and over the northern Pacific. We note, however, an abnormal overcast area around 


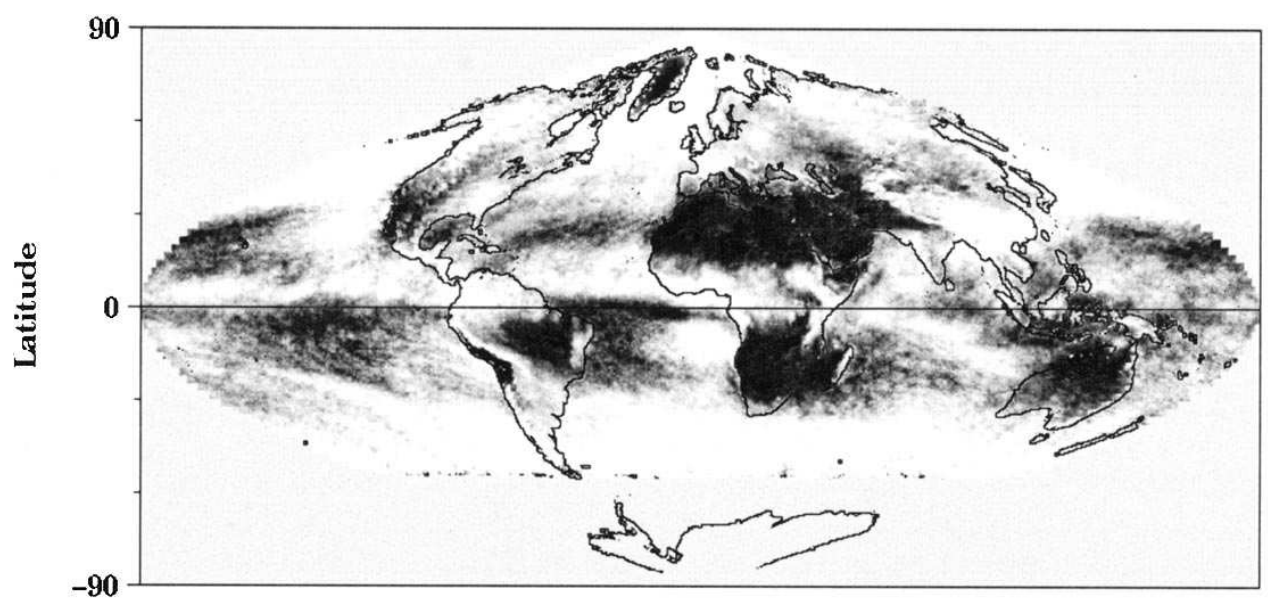

Fig. 6. POLDER level 3 monthly synthesis of cloud cover for June 1997. Coverage ranges from zero (black) to one (white) over a light gray background.

TABLE IV

Global Means of iscCP C\&D and POLDER Cloud Covers. For the D Data Set, Min and Max Give the Interannual Dispersion Among the Six Processed Years

\begin{tabular}{c|c|ccc|c}
\cline { 3 - 5 } & \multicolumn{1}{c|}{$C$} & \multicolumn{3}{|c|}{$\mathrm{D}$} & PoLdER \\
\hline Mean & Min & Mean & Max & Mcan \\
Over ocean & 0.63 & 0.65 & 0.66 & 0.68 & 0.58 \\
Over land & 0.68 & 0.68 & 0.70 & 0.72 & 0.63 \\
\hline
\end{tabular}

the North Pole corresponding, as it will be confirmed later, to a faulty cloud detection over sea ice.

Crude statistics of this cloud cover (Table IV) show that POLDER data underestimate the global cloud amount by $8 \%$ (5\%) when compared with ISCCP D2 (C2) interannual mean data sets. When comparing these cloud covers at pixel scale, we see that POLDER is always weaker over ocean, but close to the $\mathrm{C} 2$ data set over land.

A more detailed view of these statistics in terms of cloud cover distribution (Fig. 7) shows that, for POLDER and ISCCP D2 data sets, $20 \%$ of the cells have a cloud cover higher than 0.8 . However, $34 \%$ of POLDER cells have a cloud cover lower than 0.5 , whereas this percentage drops to $20 \%$ for ISCCP-D2 climatology. A closer look at the POLDER (respectively, ISCCP-D2) cloud covers shows that, over ocean, $22 \%$ (respectively, $30 \%$ ) of the cells have a coverage higher than 0.8 , while $28 \%(15 \%)$ of cells have a coverage less than 0.5. Over land, these percentages become $8 \%$ (10\%) for POLDER (ISCCP) cells with a coverage higher than 0.8 and $48 \%(32 \%)$ for cells with a coverage lower than 0.5 .

Over land, in the $60^{\circ} \mathrm{N}-60^{\circ} \mathrm{S}$ latitude range, the increase of cloud coverage observed between the C2 data set and the D2 reprocessing is mainly due to the lower brightness temperature threshold used to separate clear and cloudy cells [34]. We may thus presume that the POLDER underestimation of cloud cover over land comes from a weaker detection of thin cirrus, as it is typically observed over the Saharan desert. This can be extended for ocean observations and is coherent with the precautions included in the cloud detection algorithms to avoid aerosol contamination (see Section II).

Finally, we have checked the coherence between POLDER cloud cover and ISCCP reprocessed climatologies at the pixel scale by looking at the cloud cover differences $(\delta \mathrm{CC})$ with POLDER. Over ocean, $\delta \mathrm{CC}$ is weaker than 0.1 for $62 \%$ of the pixels while over land, this is observed for only $49 \%$ of the pixels. When the tolerance threshold is set to $\delta \mathrm{CC}<0.2$, these percentages reach $86 \%$ over ocean and $79 \%$ over land. That shows a good coherence at a global coverage scale despite the fact that i) we compare June 1997 to a six-year interannual mean and ii) POLDER has a daily global coverage, while ISCCP climatologies use multisensor data.

\section{B. Cloud Optical Thickness}

In both level 2 (with full directional properties) and level 3 processings, spatial and angular, then temporal averagings of optical thickness have been performed separately in terms of linear means and energy equivalent means (see Section III). Both sets of information are given in "ERB \& clouds" POLDER products as in ISCCP products, but we will concentrate here on the latter.

The POLDER energy averaged optical thickness for June 1997 is presented in Fig. 8. Besides the values much larger than 15 at high latitudes which are obviously due to the large reflectivity of sea-ice areas detected as overcast pixels, the 


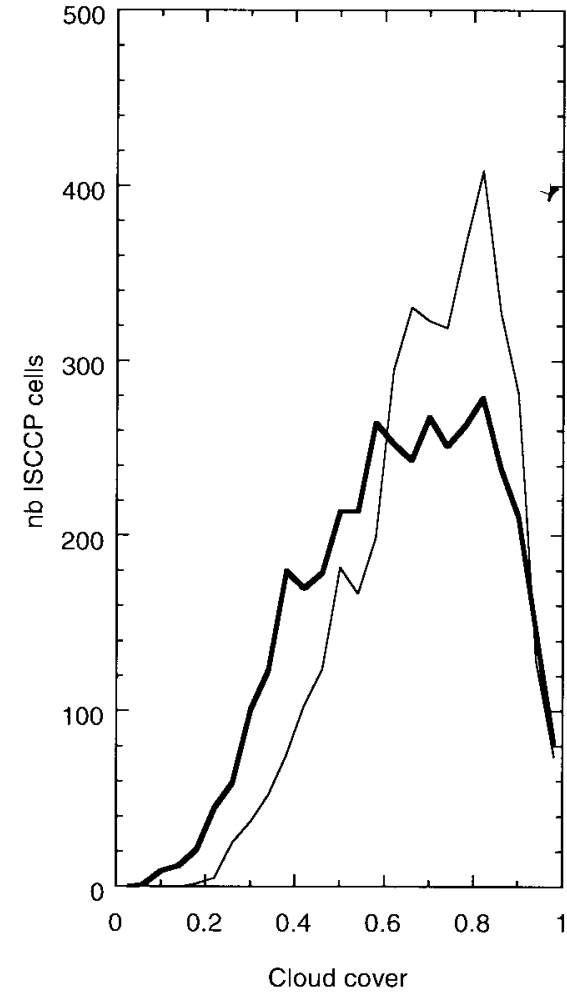

(a)

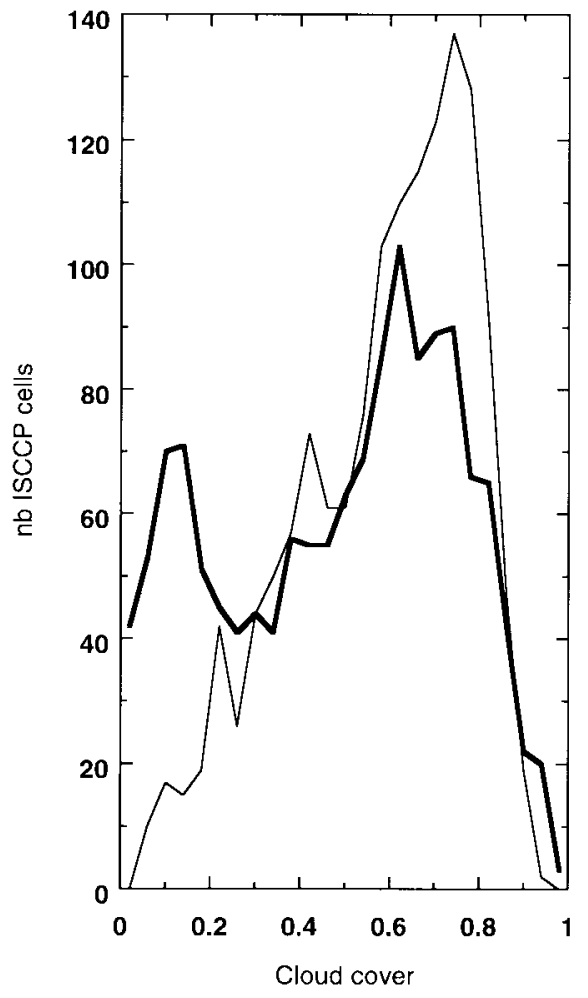

(b)

Fig. 7. Comparison of POLDER (thick solid line) and ISCCP D2 (thin solid line) cloud cover distributions (a) over ocean and (b) over land. The count axis corresponds to the number of ISCCP equal area grid cells in $4 \%$ bins.

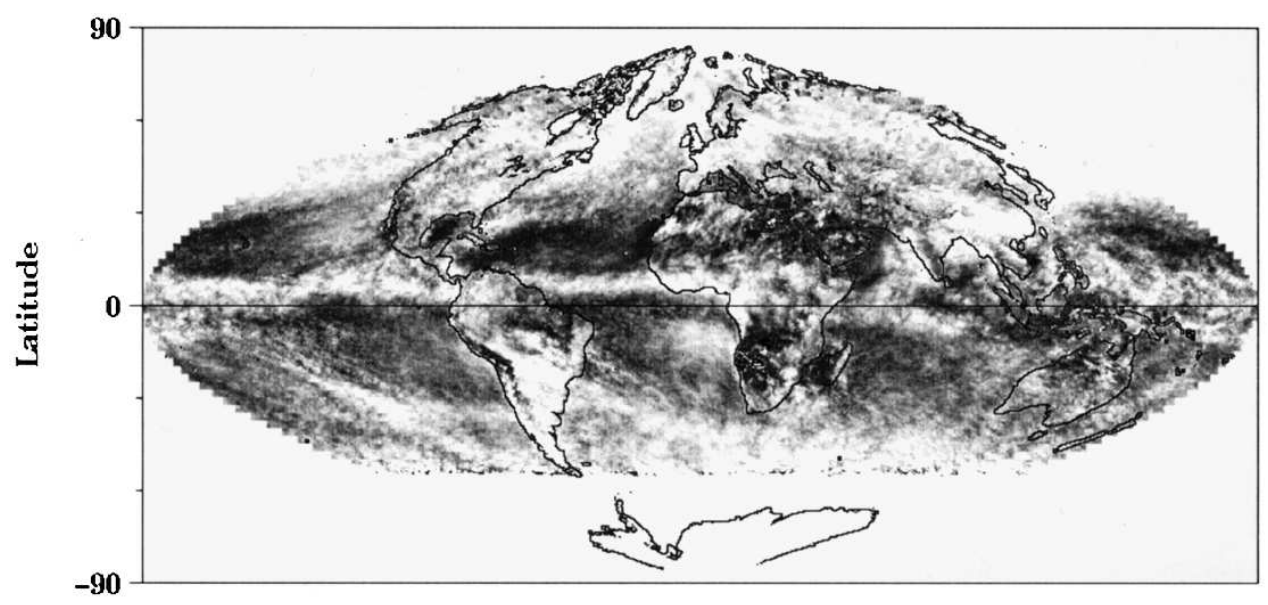

Fig. 8. POLDER level 3 monthly synthesis of cloud optical thickness (energy means) for June 1997. The scale ranges from zero (black) to 15 (white) over a light gray background.

observed optical thickness is coherent with the above-observed cloud structures and their expected regional reflectivity characteristics: high mean values all along the ITCZ, over midlatitude depression areas and for frequent thick enough cirrus banks as seen over the Sahara.

The statistical distribution of all the retrieved optical thicknesses between $60^{\circ} \mathrm{N}$ and $60^{\circ} \mathrm{S}$ is presented in Fig. 9 along with the corresponding ISCCP data. The pixel values (coded in equivalent energy amount) have been averaged, with cloud cover weighting, at the ISCCP cell scale and then converted to corresponding optical thickness for presentation. We observe a noticeable spreading of the POLDER distribution (4.66 \pm 0.64) toward higher optical thickness values, compared to ISCCP $(3.91 \pm 0.58)$. At this stage of a first comparison, we may think of different grounds for this discrepancy. First, ISCCP and POLDER present differences in the optical thickness retrieval methods as well as in the measurements. Another would be the effect of the POLDER cloud detection algorithm thresholds on thin cirrus and small or broken clouds at the subpixel scale, compared to the ISCCP rate of detection. Since optical depth averaging is only done for nonzero cloud cover, the statistical effect may be far from negligible, even for 


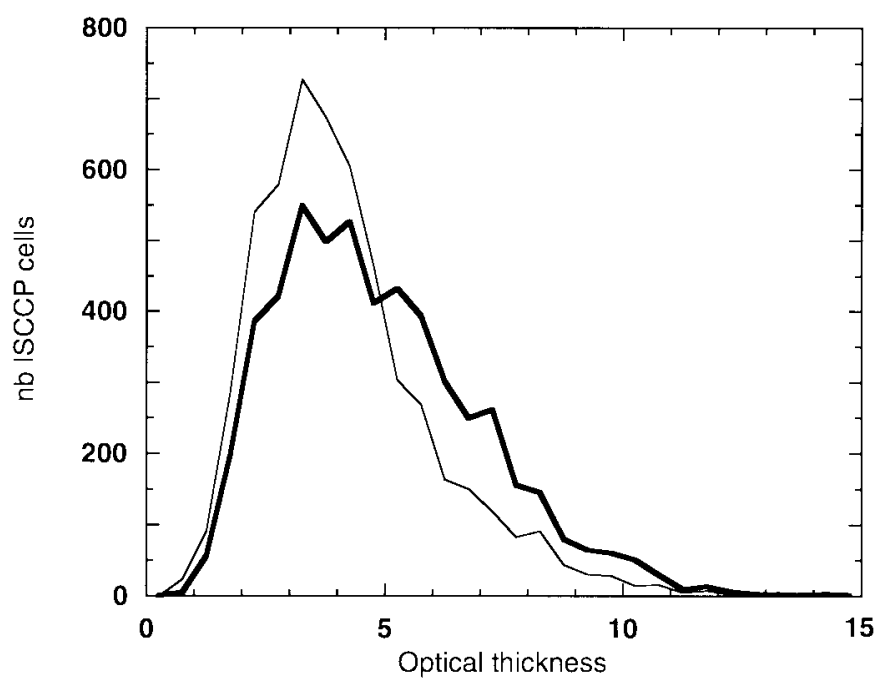

Fig. 9. Comparison of POLDER (thick solid line) and ISCCP (thin solid line) optical thickness distributions. The count axis corresponds to the number of ISCCP equal area grid cells in 0.5 bins.

energy means, and would lead toward the observed spreading over higher optical thickness values. Given the importance of optical thickness as a cloud characteristic, more precise studies are clearly needed, in particular with June 1997 ISCCP data when available.

\section{Cloud Pressure}

As explained in Section IV, two different POLDER cloud pressures ( $P_{\text {app }}$ and $P_{\text {Ray }}$ ) have been defined, using two different physical principles. We may thus expect to attain different characteristics of the usually complex cloud structures.

The POLDER mean "apparent" cloud pressure $P_{\text {app }}$ for June 1997 is presented in Fig. 10. The abnormally high values around the pole are in fact surface pressures of snow and seaice, as mentioned above. The main climatic trends of cloud top heights are easily recognizable: large areas of dense low cloud structures on subtropical west sides of main continents and the southern Indian Ocean, high cloud accumulation all along the ITCZ and over high altitude continental zones. However, but not surprisingly (see Section IV), $P_{\text {app }}$ appears systematically lower than the expected cloud "top" pressure.

This is clearly confirmed by a global statistical comparison of this retrieved pressure against ISCCP pressures (Table V). For the latter, we have chosen to confront POLDER pressures to both "adjusted cloud top pressure" (noted P78, following ISCCP D2 notation [34]) and "nonadjusted cloud top pressure" (P79). When averaged, $P_{\text {app }}$ appears very close to the uncorrected P79 pressure but significantly higher than P78.

Pressure distributions over all ICCP cells (Fig. 11) furnish further hints. First, $P_{\text {app }}$ and P78 present a very similar shape of distribution which shows, more or less clearly, three expected structures: the concentration of large stratocumulus decks with high pressure values, thick high-level clouds on the other end of the histogram, and a majority of middle/multilayered cloud structures in between. Second, there is an overall shift of $139 \mathrm{hPa}$ between $P_{\text {app }}$ and P78, the latter being expected to be close to the top cloud pressure.
This overall value is probably a complex statistical mixing of two main radiative processes: photon penetration inside cloud layers and transparency of thin upper layer to lower cloud layers or surface reflectivity (see Section IV and [42]).

The POLDER mean "Rayleigh pressure" $P_{\text {Ray }}$ for June 1997, presented in Fig. 12, is expected to be closer to the top cloud pressure (Section IV). Indeed, all the main climatic trends of known cloud top heights are enhanced when compared to $P_{\text {app }}$ : geographic extension of the high-level clouds, particularly over land, and clear higher mean values of the cloud pressure. We note, however, an abnormal amount of large $(>900 \mathrm{hPa})$ pressure values which are currently under investigation.

When $P_{\text {Ray }}$ is compared to ISCCP cloud top pressure P78 (Table V and Fig. 13) we observe a shift of $78 \mathrm{hPa}$ toward high pressure values, whereas the general trends of the pressure distribution are comparable. Given the very different radiative physics involved in the retrieval of these two cloud pressures (brightness temperature in one case and polarized visible reflectivity in the other), a detailed comparison is far beyond the scope of this paper. However, when exploring the lower pressure end of the distribution (Fig. 3) at the pixel scale, we observe that (22\%) (16\%) (36\%) of (all)(ocean)(land) ISCCP P78 pixels have a cloud top pressure weaker than 450 $\mathrm{hPa}$, while the corresponding percentages drop to $(5 \%)(4 \%)$ (7\%) for $P_{\text {Ray }}$. As observed for $P_{\text {app }}$, one part of this lack of high pressures is due to the POLDER misdetection of thin cirrus, particularly over land; another part may be interpreted as a transparency effect of the polarization due to molecules underneath high rather thin cloud layers; further studies are nonetheless needed to confirm such a statement.

At the present state of the validation, the comparisons presented above for three of the main cloud properties are encouraging and lead to rather coherent hints regarding the observed discrepancies. However, this preliminary study is limited to a single month and any conclusive statement should wait until the whole eight months of level 3 POLDER data are processed.

\section{SUMMARY AND CONCLUSION}

First results on the derivation of cloud properties from ADEOS-POLDER have been presented in this paper. The original contribution of POLDER has been emphasized for each cloud property investigated. Particular attention was given to POLDER level 2 data of November 10, 1996 and level 3 products of June 1997.

A first key result is a good correlation between the POLDER cloud detection algorithm and the Dynamical Clustering Method [37] applied to METEOSAT data. Some discrepancies appear for broken cloudiness and very thin cirrus cloud cases. However, we think that it is preferable to not allocate to an entire POLDER pixel $(6.2 \mathrm{~km} \times 6.2 \mathrm{~km})$ cloud properties that correspond only to a small fraction of the pixel. This choice can explain why our cloud cover appears to be weaker (typically by 0.08 ) than the ISCCP climatological values.

Cloud optical thickness was derived from bidirectional reflectances by using the standard water droplet model with 


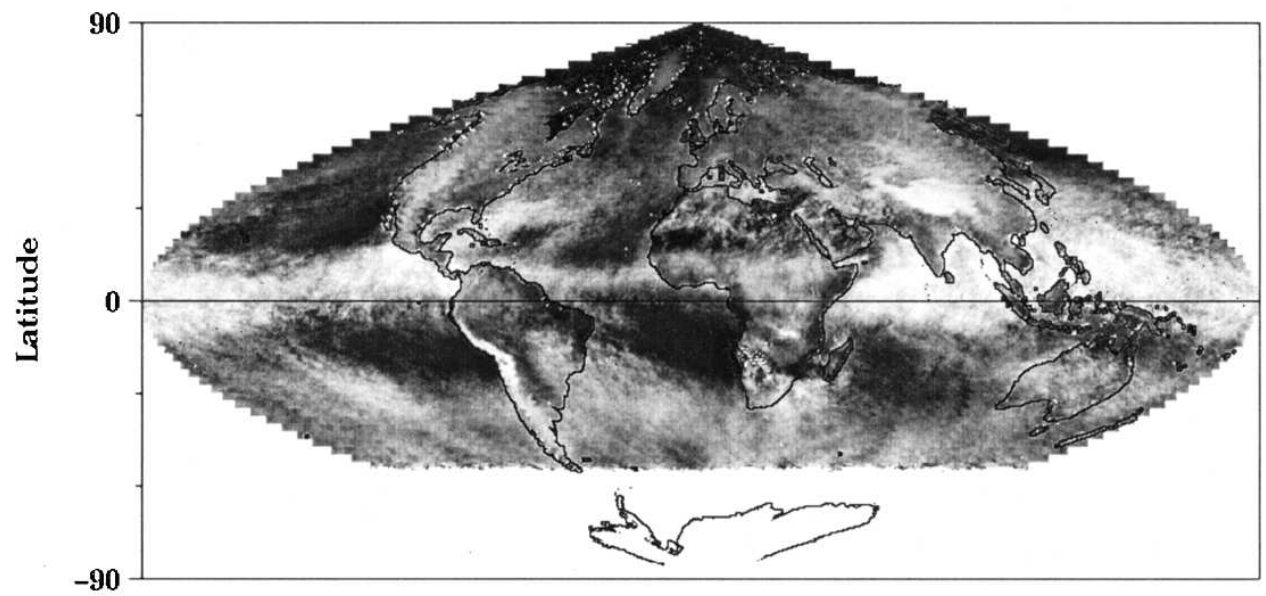

Fig. 10. POLDER level 3 monthly synthesis of apparent O2 pressure ( $\left.P_{\text {app }}\right)$ for June 1997. Pressure ranges from $200 \mathrm{hPa}$ (white) to $1000 \mathrm{hPa}$ (black).

TABLE V

Global Means and Standard Deviations (hPa) of ISCCP P78 and P79 (See Text) and POlder $P_{\text {app }}$ and $P_{\text {Ray }}$ Pressure Distributions

\begin{tabular}{l|c|c|c|c}
\cline { 2 - 5 } & P78 & $P 79$ & $P_{\text {app }}$ & $P_{\text {R:al }}$ \\
\hline All cells & $565 \pm 131$ & $670 \pm 103$ & $704 \pm 108$ & $643 \pm 135$ \\
Over ocean & $545 \pm 132$ & $660 \pm 105$ & $700 \pm 116$ & $668 \pm 137$ \\
Over land & $605 \pm 117$ & $685 \pm 94$ & $717 \pm 87$ & $585 \pm 136$ \\
\hline
\end{tabular}

an effective radius of $10 \mu \mathrm{m}$. The multidirectional capability of POLDER is demonstrated to be useful to check schemes of cloud optical thickness retrieval. As expected, the standard water droplet model is suitable for liquid water clouds and inadequate for ice clouds. This statement indirectly validates our algorithm of cloud thermodynamic phase recognition, since it was used to select these two types of clouds. The next "ERB \& clouds" algorithm planned for POLDER2 on ADEOS2 (end of 2000) should begin with the cloud phase detection; then the more adequate particle models should be used to derive the cloud optical thickness. For this purpose, different ice crystal models will be analyzed and validated in the very near future.

Two POLDER cloud pressures are derived by two different ways: the $\mathrm{O}_{2}$-apparent pressure is derived from absorption measurements in the oxygen-A band, while the Rayleigh cloud pressure makes use of spectral polarization observations. On average, the apparent pressure is weaker (typically by 60 $\mathrm{hPa}$ ) than the Rayleigh pressure. For overcast conditions, the Rayleigh pressure is expected to be close to the cloud top pressure; the $\mathrm{O}_{2}$-apparent pressure is larger by more than $100 \mathrm{hPa}$ chiefly due to the photon penetration effect inside the cloud layers. For partly cloudy conditions, the difference between the two retrieved pressures can be now negative now positive depending on the importance of the surface reflectivity.

Comparisons between POLDER and ISCCP monthly mean products were performed for the month of June. However, they are still only preliminary since the ISCCP data are not yet

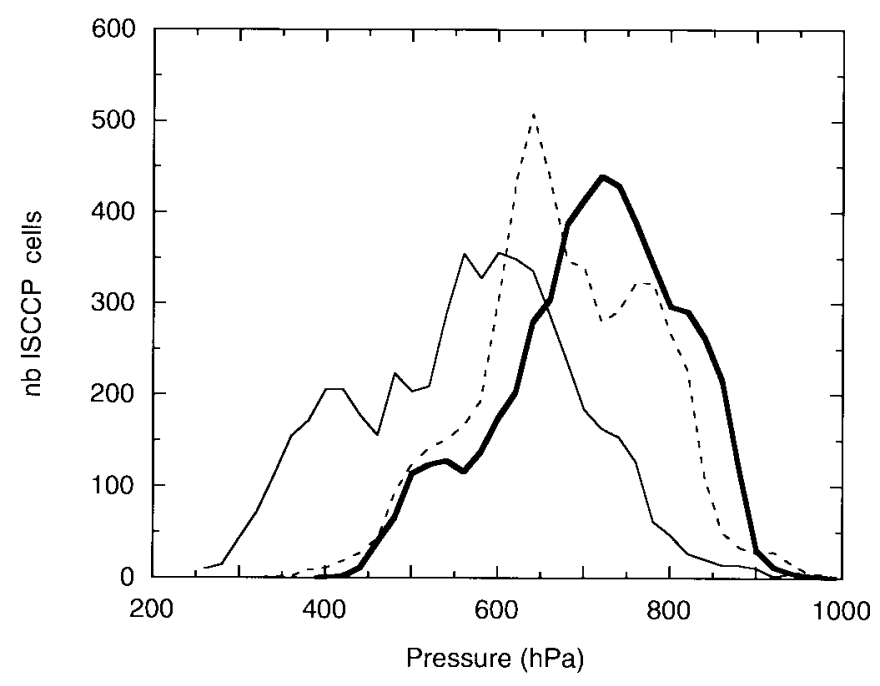

Fig. 11. Comparison of $P_{\text {app }}$ (thick solid line), ISCCP P78 pressure (thin solid line) and P79 pressure (dotted line) distributions. The count axis corresponds to the number of ISCCP equal area grid cells in $20 \mathrm{hPa}$ bins.

available for the period of the ADEOS-POLDER acquisition (November 1996-June 1997). Overall, the agreement is rather good. Differences between POLDER and ISCCP cloud optical thickness and cloud pressure certainly result for a large part from differences in the cloud detection schemes. They also result from the original characteristics of the POLDER instrument, which is complementary to usual satellite radiometers.

The multispectral multipolarization and multidirectional capabilities of POLDER thus appear useful for cloud studies. 


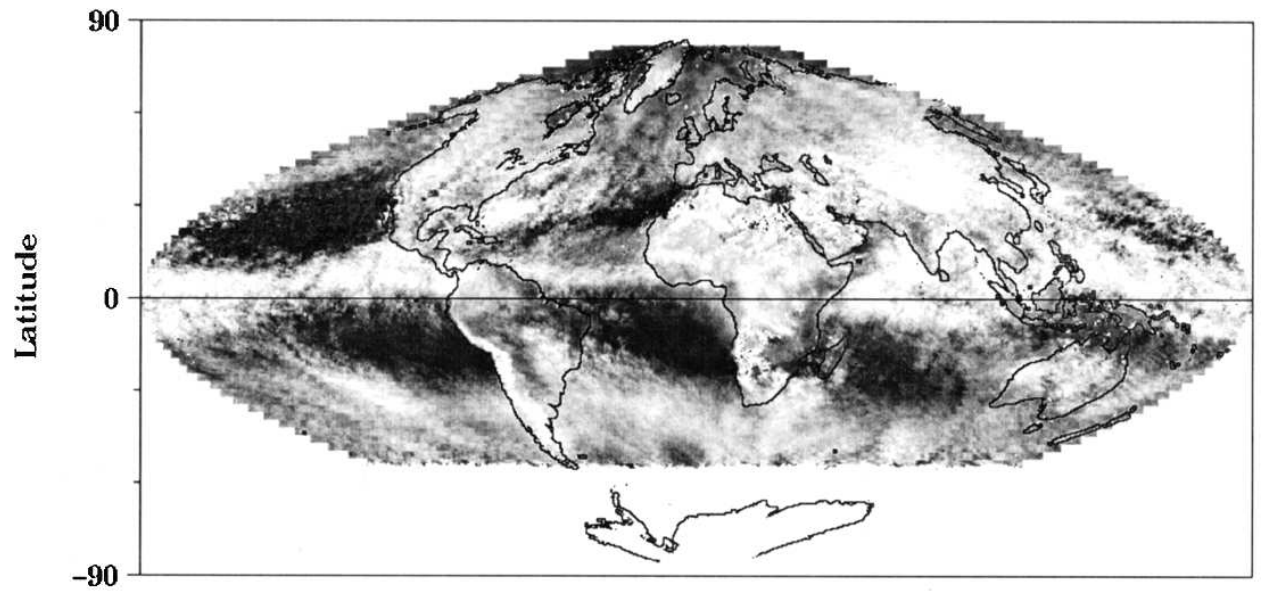

Fig. 12. As in Fig. 10 for POLDER "Rayleigh" pressure $\left(P_{\text {Ray }}\right)$.

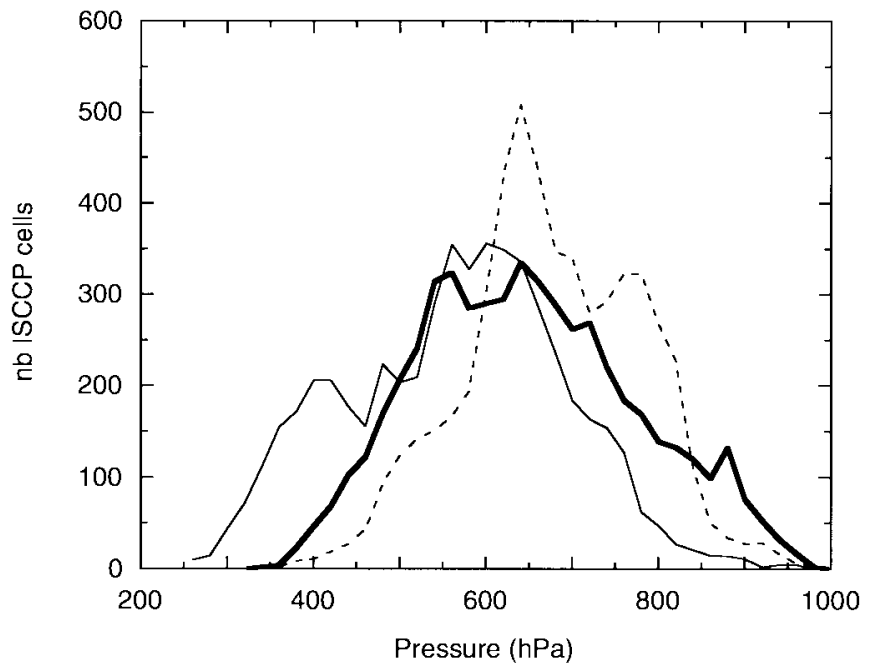

Fig. 13. As in Fig. 11 for $P_{\text {Ray }}$ (thick solid line).

Moreover, POLDER allows observing a large sampling of the BRDF (up to 14 quasi-simultaneous radiance measurements) of any scene. Hence, it makes possible the construction of angular directional models directly correlated with the retrieved cloud properties. This item is important in view of the high remaining uncertainty when inverting radiances to fluxes in the Earth Radiation Budget Experiment (ERBE) project, which is simply due to the use of limited and sometimes incorrect angular directional models [3], [2]. In the recent Tropical Rainfall Measuring Mission (TRMM) [39] and nearfuture Earth Observing System (EOS) projects [44], this fundamental problem is expected to be improved by combining broadband CERES measurements [45] with the use of narrowband moderate spatial resolution cloud imagers like Moderate Resolution Imaging Spectrometer (MODIS) [24] and Visible and Infrared Scanner (VIRS).

\section{ACKNOWLEDGMENT}

The authors wish to thank A. Lifermann for her comments on the manuscript. They also gratefully acknowledge Dr. I. Melnikova and two anonymous referees for their very helpful comments and suggestions.

\section{REFERENCES}

[1] A. Arking, "Latitudinal distribution of cloud cover from TIROS III photographs," Science, vol. 143, pp. 569-572, 1964.

[2] D. G. Baldwin and J. A. Coakley, Jr, "Consistency of Earth radiation budget experiment bidirectional models and the observed anisotropy of reflected sunlight," J. Geophys. Res., vol. 96, pp. 5195-5207, 1991.

[3] B. R. Barkstrom, E. F. Harrison, and R. B. Lee, "Earth radiation budget experiment. Preliminary seasonal results," EOS, vol. 71, pp. 297-305, 1990.

[4] F. M. Bréon and P. Goloub, "Cloud droplet effective radius from spaceborne polarization measurements," Geophys. Res. Lett., vol. 25, pp. 1879-1992, 1998.

[5] F. M. Bréon and S. Colzy, "Cloud detection from the spaceborne POLDER Instrument and validation against synoptic observations," $J$. Appl. Meteorol., to be published.

[6] G. Brogniez, "Light scattering by finite hexagonal crystals arbitrarily oriented in space," in Proc. IRS'88, J. L Lenoble, J. F. Geleyn, and A. Deepak, Eds., Hampton, VA, 1988, p. 64.

[7] J.-C. Buriez, C. Vanbauce, F. Parol, P. Goloub, M. Herman, B. Bonnel, Y. Fouquart, P. Couvert, and G. Sèze, "Cloud detection and derivation of cloud properties from POLDER," Int. J. Remote Sens., vol. 18, pp. 2785-2813, 1997.

[8] R. D. Cess et al., "Intercomparison and interpretation of climate feedback processes in 19 atmospheric general circulation models," J. Geophys. Res., vol. 95, pp. 16601-16610, 1990.

[9] _ "Cloud feedback in atmospheric general circulation models: An update," J. Geophys. Res., vol. 101, pp. 12791-12794, 1996.

[10] L. H. Chambers and B. A. Wielicki, "Accuracy of independent pixel approximation for satellite estimates of oceanic boundary layer cloud optical depth," J. Geophys. Res., vol. 102, pp. 1779-1794, 1997.

[11] R. J. Charlson, S. E. Schwartz, J. M. Hales, R. D. Cess, J. A. Coackley, Jr., J. E. Hansen, and D. J. Hofmann, "Climate forcing by anthropogenic aerosols," Science, vol. 255, pp. 423-430, 1992.

[12] H. Chepfer, G. Brogniez, L. Sauvage, P. H. Flamant, V. Trouillet, and J. Pelon, "Remote sensing of cirrus radiative parameters during EUCREX'94. Case study of Apr. 17, 1994. Part 1: Microphysical modelization," Mon. Wea. Rev., vol. 127, pp. 504-519, 1999.

[13] P. Y. Deschamps, F. M. Breon, M. Leroy, A. Podaire, A. Bricaud, J. C. Buriez, and G. Sèze, "The POLDER mission: Instrument characteristics and scientific objectives," IEEE Trans. Geosci. Remote Sensing, vol. 32, pp. 598-615, 1994.

[14] J. Descloitres, J.-C. Buriez, F. Parol, and Y. Fouquart, "POLDER observations of cloud bidirectional reflectances compared to a planeparallel model using the ISCCP cloud phase functions," J. Geophys. Res., vol. 103, pp. 11411-11418, 1998.

[15] P. Goloub, J.-L. Deuzé, M. Herman, and Y. Fouquart, "Analysis of the POLDER polarization measurements performed over cloud covers," IEEE Trans. Geosci. Remote Sensing, vol. 32, pp. 78-88, 1994.

[16] P. Goloub, H. Chepfer, M. Herman, G. Brogniez, and F. Parol: "Use of polarization for clouds study," in Proc. SPIE, 1997, vol. 3121, pp. $330-341$.

[17] Q. Han, W. B. Rossow, and A. A. Lacis, "Near-global survey of effective droplet radii in liquid water clouds using ISCCP data," J. Climate, vol. 7, pp. 465-497, 1994 
[18] J. E. Hansen and L. D. Travis, "Light scattering in planetary atmospheres," Space Sci. Rev., vol. 16, pp. 527-610, 1974.

[19] J. E. Hansen, "Multiple scattering of polarized light in planetary atmospheres. Part II. Sunlight reflected by terrestrial water clouds," $J$. Atmos. Sci., vol. 28, pp. 1400-1426, 1971.

[20] E. F. Harrison, P. Minnis, B. R. Barkstrom, V. Ramanathan, R. D. Cess, and G. G. Gibson, "Seasonal variations of cloud radiative forcing derived from the Earth radiation budget experiment," J. Geophys. Res., vol. 95, pp. 18687-18703, 1990.

[21] A. J. Heymsfield, "Cirrus unicinus generating celles and evolution of cirriform clouds. Part I: Aircraft observations of the growth of the ice phase," J. Atmos. Sci., vol. 32, pp. 799-807, 1975.

[22] J. T. Houghton, G. J. Jenkins, and J. J. Ephraums, Eds., "Climate change: The IPCC scientific assessment," in World Meteorological Organization/United Nations Environment Programme. Cambridge, U.K.: : Cambridge Univ. Press, 1990, p. 364.

[23] R. S. Kandel, J. L. Monge, M. Viollier, L. A. Pakhomov, V. I. Adasko, R. G. Reitenbach, E. Raschke, and R. Stuhlmann, "The ScaRaB project: Earth radiation budget observations from the Meteor satellites," World Space Congress (Washington)-COSPAR Symp. A.2-S, Adv. Space Res. vol. 14 , no. 1 , pp. 47-54, 1994

[24] M. D. King, Y. J. Kaufman, W. P. Menzel, and D. Tanré, "Remote sensing of cloud, aerosol, and water vapor properties from the moderate resolution imaging spectrometer (MODIS)," IEEE Trans. Geosci. Remote Sensing, vol. 30, pp. 2-27, Jan. 1992.

[25] T. Kobayashi, "Effects due to cloud geometry on biases in the albedo derived from radiance measurements," J. Climate, vol. 6, pp. 120-128, 1993.

[26] X. Lin and J. A. Coaklley, "Retrieval of properties for semitransparent clouds from multispectral infrared imagery data," J. Geophys. Res., vol. 98, pp. 18501-18514, 1993

[27] W. P. Menzel, D. P. Wylie, and K. L. Strabala, "Seasonal and diurnal changes in cirrus clouds in four years of observations with the VAS," J. Appl. Meteorol., vol. 31, pp. 370-385, 1992.

[28] M. I. Mishchenko, W. B. Rossow, A. Macke, and A. A. Lacis, "Sensitivity of cirrus cloud albedo, bidirectional reflectance and optical thickness retrieval accuracy to ice particle shape," J. Geophys. Res., vol. 101, pp. 16973-16985, 1996.

[29] J. L. Raffaelli and G. Sèze, "Cloud type separation using local correlation between visible and infrared satellite images," in Passive Infrare Remote sensing of clouds and the atmosphere III, Proc. SPIE, vol. 2578, pp. 61-67, 1995

[30] V. Ramanathan, R. D. Cess, E. F. Harrison, P. Minnis, B. R. Barkstrom, E. Ahmad, and D. Hartmann, "Cloud radiative forcing and climate: Results from the Earth radiation budget experiment," Science, vol. 243, pp. 57-63, 1989.

[31] D. W. Reynolds and T. H. Vonder Harr, "A bi-spectral method for cloud parameter determination,” Mon. Wea. Rev., vol. 105, pp. 446-457, 1977.

[32] W. B. Rossow, L. C. Garder, and A. A. Lacis, "Global, seasonal cloud variations from satellite radiance measurements. Part I: Sensitivity of analysis," J. Climate, vol. 2, pp. 419-458, 1989.

[33] W. B. Rossow and R. A. Schiffer, "ISCCP cloud data products," Bull. Amer. Meteorol. Soc., vol. 6, pp. 2394-2418, 1991.

[34] W. B. Rossow, A. W. Walker, D. E. Beuschel, and M. D. Roiter, "International satellite cloud climatology project (ISCCP). Documentation of new cloud datasets," WMO/TD 737, World Meteorolog. Org., 1996, p. 115.

[35] L. Sauvage, H. Chepfer, V. Trouillet, P. H. Flamant, G. Brogniez, J. Pelon, and F. Albers, "Remote sensing of cirrus radiative parameters during EUCREX'94. Case study of Apr. 17, 1994. Part 1: Observations," Mon. Wea. Rev., vol. 127, pp. 486-503, 1999.

[36] C. A. Senior and J. F. B. Mitchell, "Carbon dioxide and climate: The impact of cloud parameterization," J. Climate, vol. 6, pp. 393-418, 1993.

[37] G. Sèze and M. Desbois, "Cloud cover analysis in satellite imagery using spatial and temporal characteristics of the data," J. Climate Appl. Meteorol., vol. 26, pp. 287-303, 1987.

[38] G. Sèze, C. Vanbauce, J.-C. Buriez, F. Parol, and P. Couvert, "Comparison of the POLDER cloud detection over ocean with a METEOSAT cloud classification," in Proc. AMS'98, Paris, France, May 25-29, 1998 , pp. 500-503.

[39] J. Simpson, R. F. Adler, and G. R. North, "A proposed tropical rainfall measuring mission (TRMM) satellite," Bull. Amer. Meteorol. Soc., vol. 69, pp. 278-295, 1988 .

[40] W. L. Smith and C. M. R. Platt, "Comparison of satellite-deduced cloud heights with indications from radiosonde and ground-based measurements," J. Appl. Meteor., vol. 17, pp. 1796-1802, 1978.

[41] J. D. Spinhirne and T. Nakajima, "Glory of clouds in the near-infrared," Appl. Opt., vol. 33, pp. 4652-4662, 1994.
[42] C. Vanbauce, J. C. Buriez, F. Parol, B. Bonnel, G. Sèze, and P. Couvert, "Apparent pressure derived from ADEOS-POLDER observations in the oxygen A-band over ocean," Geophys. Res. Lett., vol. 25, pp. 3159-3162, 1998.

[43] M. Vespérini, F. M. Bréon, and D. Tanré, "Atmospheric water vapor content from POLDER spaceborne measurements," this issue, pp. $1613-1619$.

[44] B. A Wielicki, R. D. Cess, M. D. King, D. A. Randall, and E. F. Harrison, "Mission to Planet Earth: Role of clouds and radiation in climate," Bull. Amer. Meteorol. Soc., vol. 76, pp. 2125-2152, 1995.

[45] B. A Wielicki and B. R. Barkstrom, "Cloud and the Earth's radiant energy system (CERES): An Earth observing system experiment," in 2nd Symp. Global Change Studies, New Orleans, LA, Amer. Meteor. Soc., 1991, pp. 11-16.

[46] M. C. Wu, "Remote sensing of cloud-top pressure using reflected solar radiation in the oxygen-A band," J. Clim. Appl. Meteorol., vol. 24, pp. $539-546,1985$.

Frédéric Parol, for a photograph and biography, see this issue, p. 1566

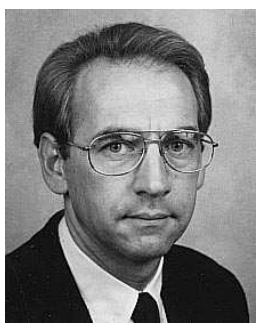

Jean-Claude Buriez received the M.S. degree in physics in 1968 and the "Doctorat d'Etat" in physics in 1981, both from the University of Lille, France.

$\mathrm{He}$ is currently a Professor of physics at the University of Lille and a Researcher at the Laboratoire d'Optique Atmosphérique. Before 1981, he worked on radiative transfer theory of inhomogeneous scattering atmospheres to analyze planetary spactra. Since then his research has focused on the remote sensing of cloud properties using space- and ground-based instruments. His scientific interests include the influence of clouds on radiation in climate modeling. He is in charge of the inversion of POLDER measurements for cloud and radiative budget analysis.

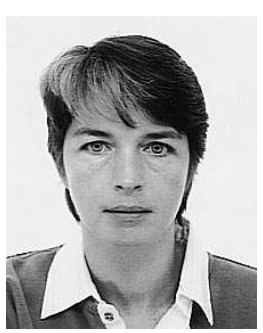

Claudine Vanbauce received the M.Sc. degree in physics in 1988 and the Ph.D. degree in atmospheric physics from the University of Lille, France, in 1992 for studies about remote sensing of fog.

During 1993, she worked on a Centre National d'Etudes Spatiales (CNES) Post-Doctoral subject devoted to the possibility of detection and classification of clouds from multispectral and multiangular POLDER data. She is currently an Assistant Professor of physic and a Researcher employed at the Laboratoire d'Optique Atmospherique, Lille, France. She participated in the POLDER "ERB \& Clouds" line algorithms development and in the validation of associated products.

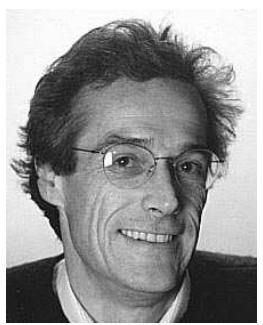

Pierre Couvert received the "Doctorat de 3ième cycle" in nuclear physics in 1974 and the "Doctorat d'Etat" in 1982.

From 1974 to 1993 , he worked mainly at the Laboratoire National Saturen, Saclay, France, as a member of the Nuclear Physics Department of the Commissariat à l'Energie Atomique. From 1982 to 1984, he spent two sabbatical years at TRIUMF, Vancouver, B.C., Canada. His domain of research was mainly devoted to nucleon scattering and meson production in nuclei. In 1994, he turned to earth sciences by joining the Laboratoire des Sciences du Climat et de l'Environnement of Saclay as a Researcher and Member of the POLDER project. In charge of the technical aspects of the "Earth Radiation Budget and Clouds" POLDER data processing line with the Centre National d'Etude Spatiale, Toulouse, he participates in the validation of the first POLDER data with the scientific team of the Laboratoire d'Optique Atmosphérique, Lille. 


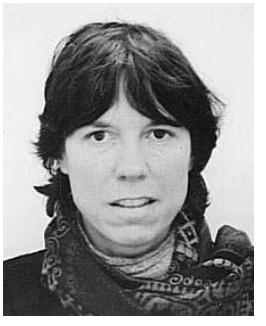

Geneviève Sèze received the $\mathrm{Ph} . \mathrm{D}$. degree in computer science from the University of Paris VI, France, in 1977.

In 1978, she joined the Laboratoire de Météorologie Dynamique (LMD) of the Centre National de la Recherche Scientifique. In 1985 and 1986, she was a Visiting Scientist at the Goddard Institute for Space Studies, New York, where she also collaborated with the International Satellite Cloud Climatology Program (ISCCP) team. In November 1989, she was selected as a member of the First ISCCP Regional Experiment (FIRE) Science Team. At LMD, she conducts research on cloud cover analyses from satellite observation and the validation of Global Circulation Model cloud cover. She participates in the definition and development of future space missions dedicated to cloud cover analyses. For the POLDER project, she is in charge of the analysis and the validation of the cloud cover.
Philippe Goloub, for photograph and biography, see p. 525 of the January 1999 issue of this TransACTIONS.

Sylvain Cheinet graduated from Ecole Polytechnique, Palaiseau, France, in 1994. In 1998, he received the M.S. degree in atmospheric physics from the University of Lille, France, where he participated in the exploitation of POLDER products with the working group "Earth Radiation Budget \& Clouds" of the Laboratoire d'Optique Atmosphérique. He is currently pursuing the Ph.D. degree in the Laboratoire de Météorologie Dynamique (working group: Modélisation Du Climat), whose topic is to determine the influence of cloud parameterization in the General Circulation Model of the LMD. 